\title{
Use of Flat Interwoven Wooden Strips in Architecture and Construction. Simulation and Optimization Using 3D Digital Models
}

\author{
Amaia Casado ${ }^{1, *}$, Antonio Sánchez ${ }^{1}$, Cristina Marieta ${ }^{2} \mathbb{D}$ and Iñigo Leon ${ }^{1, *} \mathbb{D}$ \\ 1 Department of Architecture, University of the Basque Country UPV/EHU, Plaza Oñati 2, \\ 20018 Donostia-San Sebastián, Spain; antonio.sanchez@ehu.eus \\ 2 Department of Chemical and Environmental Engineering, Faculty of Engineering, University of the Basque, \\ Country UPV/EHU, Plaza Europa 1, 20018 Donostia-San Sebastián, Spain; cristina.marieta@ehu.eus \\ * Correspondence: amaia.casado@ehu.eus (A.C.); inigo.leon@ehu.eus (I.L.)
}

Citation: Casado, A.; Sánchez, A.; Marieta, C.; Leon, I. Use of Flat Interwoven Wooden Strips in Architecture and Construction. Simulation and Optimization Using 3D Digital Models. Sustainability 2021, 13, 6383. https://doi.org/10.3390/ su13116383

Academic Editor: Luisa Molari

Received: 2 May 2021

Accepted: 2 June 2021

Published: 4 June 2021

Publisher's Note: MDPI stays neutral with regard to jurisdictional claims in published maps and institutional affiliations.

Copyright: (c) 2021 by the authors. Licensee MDPI, Basel, Switzerland. This article is an open access article distributed under the terms and conditions of the Creative Commons Attribution (CC BY) license (https:/ / creativecommons.org/licenses/by/ $4.0 /)$.

\begin{abstract}
This research aims to promote the use of natural materials in construction. Its purpose is to rediscover the interlacing of flat wooden strips. Attending to environmental criteria, it focuses on the study of wood from a locally produced tree, the chestnut, in the north of Spain. However, the proposed methodology can be universally replicated with local wood productions anywhere. The interweaving of flat wooden strips is linked to traditional basketry, which is at serious risk of disappearing in many places. A combined method based on the design of interlaced artifacts is proposed. For this purpose, the mechanical characteristics of the specific material tested were analyzed in advance. The elastic limit of the material was obtained, and this allowed simulating and optimizing the maximum curvatures of the flat strips in a 3D digital model. New geometric shapes were designed with new interlacing wefts and were built with the tested material. The digital models used serve as a record of the artifacts built, and can be posted on web platforms so that they can be universally replicated. This will allow for the preservation of this heritage of built artifacts using basketry techniques, enabling the proposed objective to be achieved.
\end{abstract}

Keywords: basketry; flat strip of wood; chestnut tree; 3D models; tensile strength; curvature

\section{Introduction}

Construction is one of the most resource-intensive sectors. Only in Europe, buildings represent $40 \%$ of the total energy consumed and produce $35 \%$ of all greenhouse gas emissions [1]. In addition, construction waste accounts for $33 \%$ of the total waste generated. Spain is the European Union country that consumes the most resources for construction [2]. It is essential to reduce the energy demand in buildings, using natural and recycled materials with low industrialization [3].

Taking this background information into account, the final purpose of this work is to show the usefulness of natural materials for architecture and construction. Research focused on the use of interwoven wood is presented in order to understand and expand its potential. Its aim is not to show an emerging material, but to rediscover a traditional material and technique with a new approach. Its updated applications are explored in a digital era where, at an environmental level, it is necessary to use sustainable natural materials from the area called "Km 0" [4]. For this reason, the research starts by analyzing the use of interlaced wood in construction at an international level, but it is defined in a local development, associated with the use of chestnut wood in the Basque Country, in northern Spain. As it will be verified, after studying the documentary analysis carried out, the methods, specifically described for this material and for this area, can be replicated worldwide. Interlaced wood has been used as a traditional construction material in many parts of the world. Its use on facades, roofs, interior partition walls, or for decoration and 
furniture can still be appreciated. Its implementation is linked to expert artisans specialized in traditional basketry, an ancestral technique that has been developed for thousands of years in many different countries [5]. The problem is that the mass appearance of products made of plastic fibers is creating a crisis for craft basketry workshops, a rural and urban industry of great importance. It is a profession that has been passed down from generation to generation, and there is a real risk of extinction in many places.

The main objective of this research focuses on three aspects: first, the analysis and documentation of traditional techniques and artifacts to preserve the existing heritage; second, the rediscovery of braiding natural fiber materials for sustainable constructions; and third, the design, implementation, and evaluation of new frames and shapes using 3D digital models. 3D models will be produced to be able to undertake new construction systems made with these materials. The mechanical and physical behavior of the material will be tested after an experimental characterization. Craft constructions are developed in most cases using the trial and error method, and lack an integral scientific basis. The aim is to endorse traditional techniques by means of a scientifically based experiment. An example of this are the conclusions, which state that, as the wood processing temperature increases, there is an increase in the properties of the materials. Another important aspect is that these 3D digital models can contain all the information about the assembly, the stresses, the material, etc. Therefore, its preservation is guaranteed without having to depend on the transmission from generation to generation of a specific family of artisans. The results of the research and the method used can promote a greater use of these materials in construction, thus preventing the disappearance of an artisan heritage in many parts of the world.

This article has the following structure. It begins with this Introduction, where the purpose of the work is presented. Next are two sections that strengthen the context, interest, and possibilities of applying this research. Following these, the Materials and Methods, the Results with the Discussion and the Conclusions are presented.

\section{Reference Architectural Works Built with Interwoven Wooden Elements}

One of the important challenges of primitive man was to be able to join various pieces together, such as, for example, a stone and a piece of wood to make a hatchet. This could be done by braiding fibers. To obtain an effective solution, this had to be based on the nearest references from the natural environment itself. One of them could be the nests that many birds build by interlacing vegetable fibers. To construct a shelter, many aboriginal people use the same materials as animals, but regardless of whether the builder is human or animal, each material has optimal structural forms [6]. Throughout history, interwoven architecture has used the manual techniques and materials of traditional basketry in its constructions. Countless architectural elements have been created, such as furniture, facades, and roofs. These elements have traditionally been of simple construction with geometric shapes controllable by the artisan (Figure 1a) [7]. Internationally, there are many renowned architects who have built with interlaced natural materials. To reinforce this argument, extracted from the documentary analysis of manifold architectural projects, some key references will be shown. Some works by the Japanese architect, Shigeru Ban, winner of the 2014 Pritzker Prize, the "Nobel Prize for Architecture", stand out. This is a clear example of the different uses of natural fiber interlacing with a predominance of wooden strips. In 2014, Ban built temporary shelters in Cebu, Philippines with braided strips made from local coconut trees, following the devastation caused by Typhoon Haiyan in November 2013 (Figure 1b). 


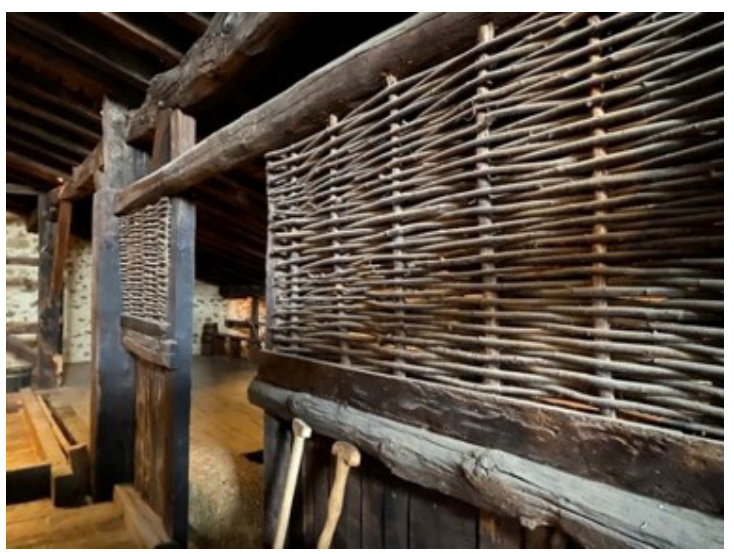

(a)

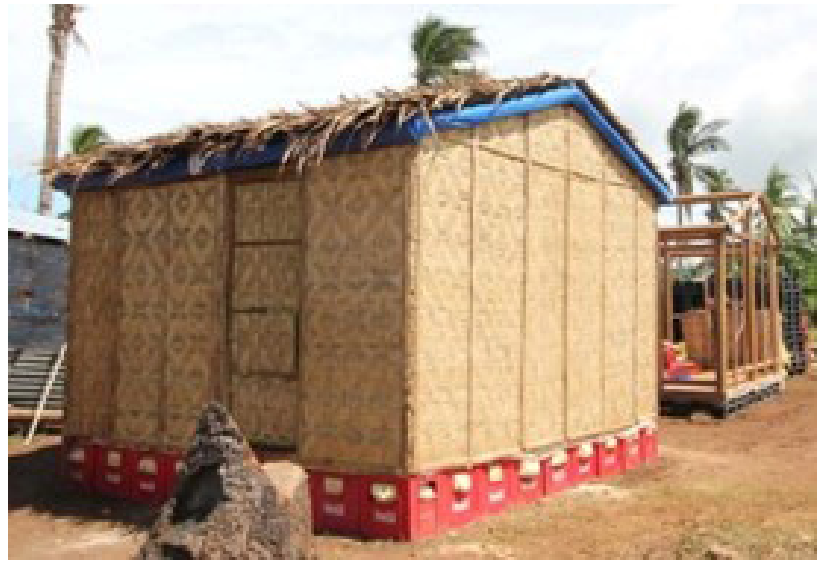

(b)

Figure 1. (a) Interior partition of the Basque farmhouse "Igartubeiti" made with basketry techniques [7]; (b) Temporary shelters in Cebu, Philippines [8].

Another example of these constructions is the Spanish Pavilion for the 2010 World Expo in Shanghai, by the Spanish architecture studio EMBT (Figure 2a). The shapes designed for the envelope were made with interwoven panels using traditional basketry techniques. This design links important concepts such as identity, tradition, and sustainability. The Imai Hospital Daycare Center in Odate, Japan, also designed by Shigeru Ban, takes a basketry object as inspiration for the constructive and structural solution built with flat wooden strips (Figure 2b).

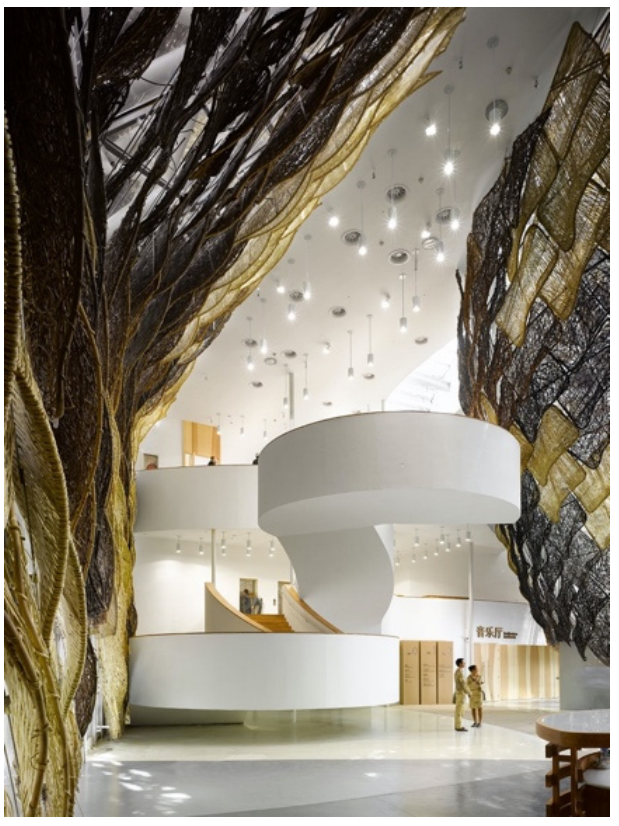

(a)

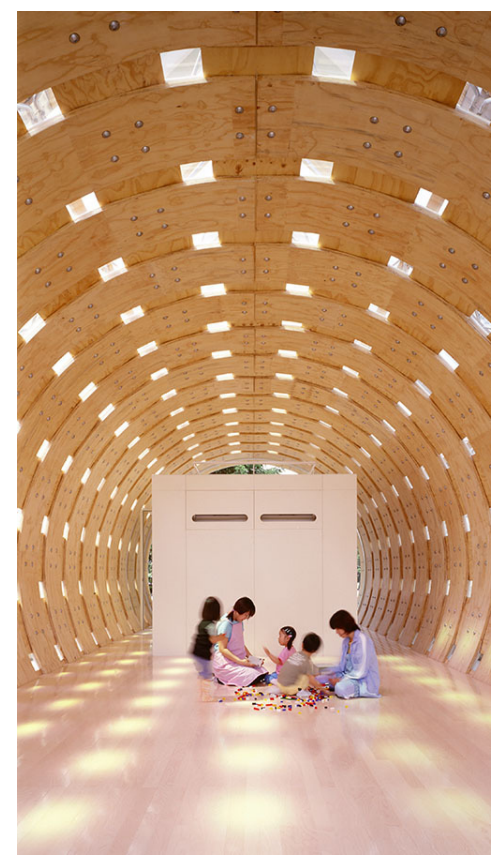

(b)

Figure 2. (a) Spanish Pavilion for the 2010 World Expo in Shanghai [9]; (b) Imai Hospital Daycare Center in Odate, 2001 [10].

Another example of a woven wood panel facade is the Aspen Museum in Colorado, USA (Figure 3a). The interior atmosphere of the building gives the sensation of being inside a basketry creation. The rectangular frame of this facade has been tested and made to scale by the authors, with the flat chestnut wood strips analyzed in this study (Figure 3b). This pattern serves as the basis for other, more complex geometric shapes developed. 


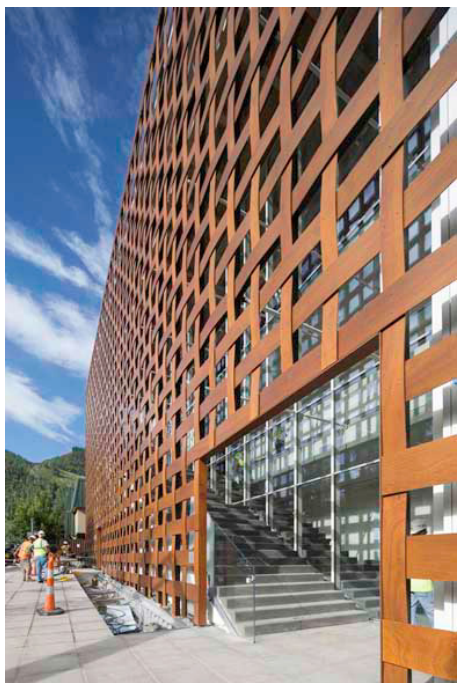

(a)

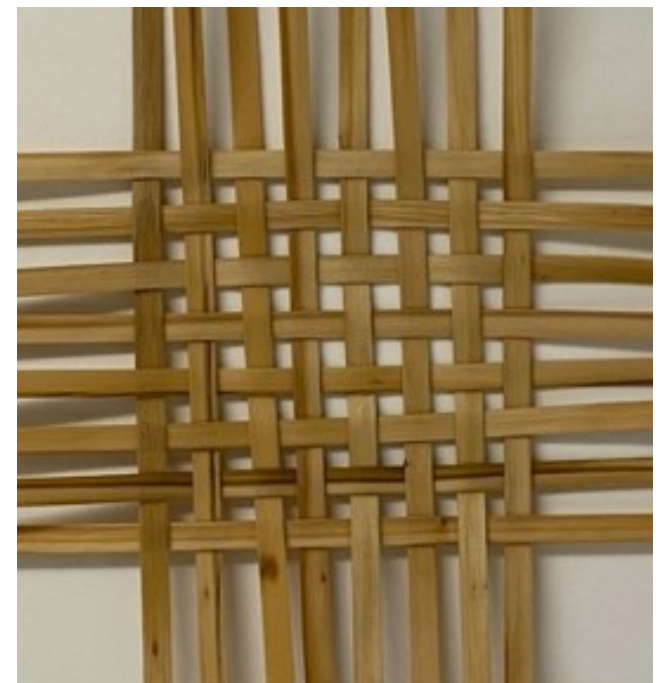

(b)

Figure 3. (a) Envelope interweaving flat strips of wood, Aspen Museum in Colorado, Shigeru Ban, 2014 [11]; (b) Preparation of this rectangular weft with the flat chestnut wood strips studied herein (source: authors).

An example of great modernity and technical complexity is the Pompidou Center in Metz, France (Figure 4a). The roof is made from laminated wood, woven into hexagons, inspired by a bamboo-woven Chinese hat. The digital age and 3D modeling software have permitted the control and rediscovery of more organic forms close to nature. These digital models allow replicating these new ways of building using traditional natural materials such as the flat chestnut wood strips used in this research (Figure 4b).

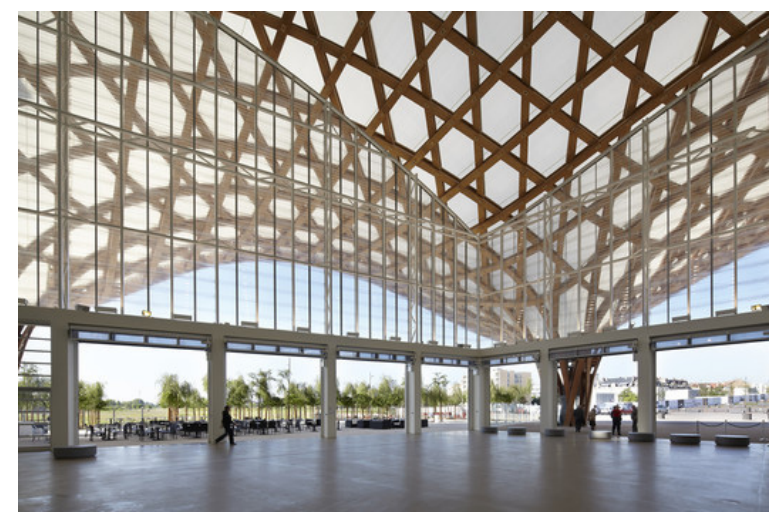

(a)

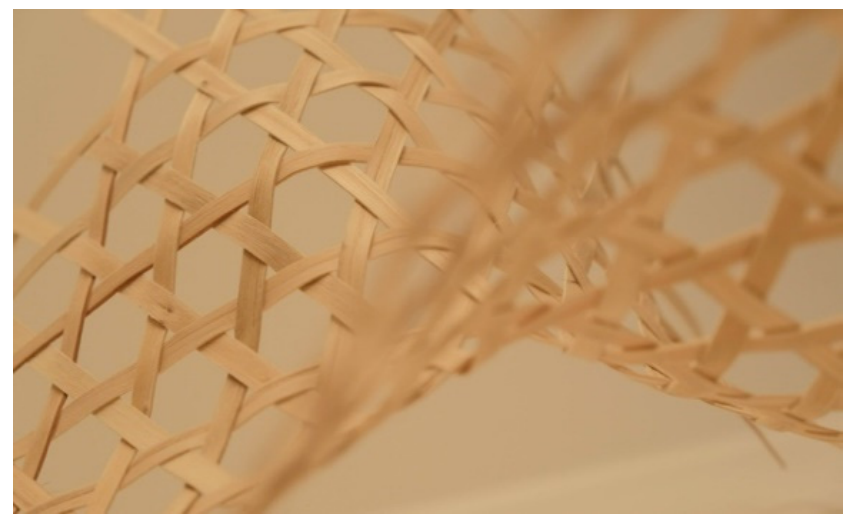

(b)

Figure 4. (a) Structure interlacing strips of wood following the Kagome basketry pattern, Shigeru Ban, 2010 [12]; (b) This weft made with the flat chestnut wood strips studied herein (source: authors).

Another important element within buildings is the construction of decorative artifacts and furniture. There are many examples from famous international architects who have designed furniture constructed by interlacing strips based on traditional basket weaving. This tradition can be analyzed in numerous prestigious chairs such as Armchair 45 with cane seat by the architect Alvar Aalto (Figure 5a). New furniture designs that use flat chestnut wood strips can already be seen in the Basque Country (Figure 5b). The fact that the construction is based on the artisan's know-how, and not on a design using 3D digital models, limits the result to simple shapes and to 2-strip rectangular frames. 


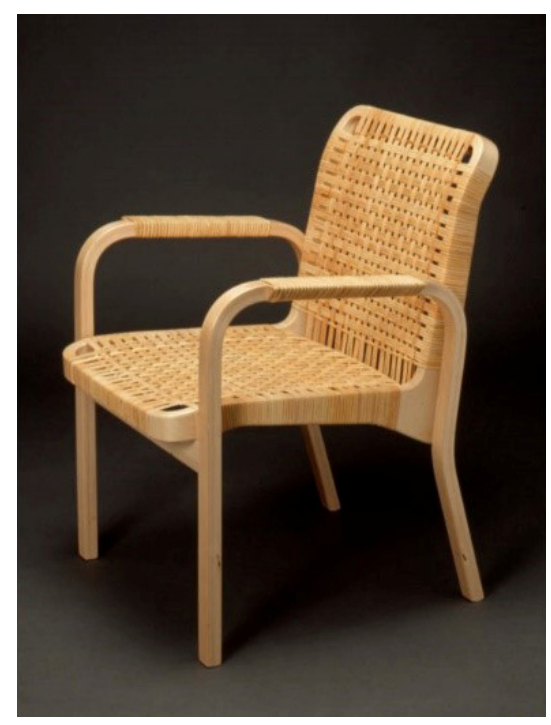

(a)

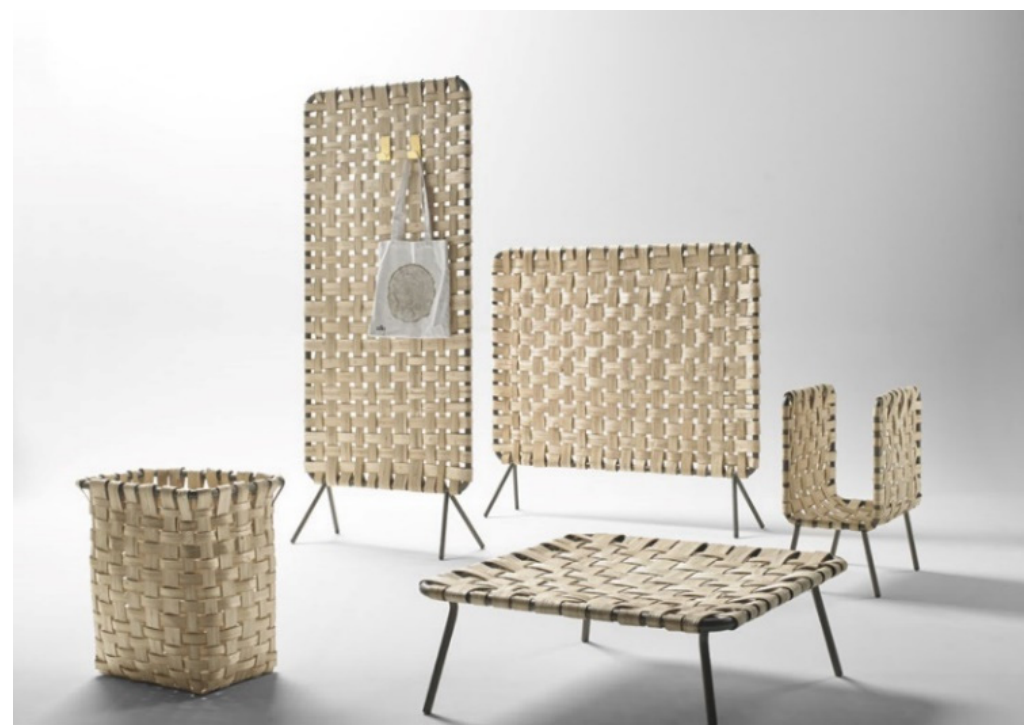

(b)

Figure 5. (a) Armchair 45 with cane seat, 1947, Photo: Matti Kapanen [13]; (b) New furniture and accessories designed using interwoven flat chestnut strips in the Basque Country; Product: Zumitz, Irazoki-Lizaso [14].

\section{Evolution of Traditional Basketry Wefts and Geometries with 3D Digital Modeling}

Traditional basketry has limitations for several reasons. Interlacing requires defining a pattern or weft for weaving natural fibers that must adapt to a geometric shape (Figure 6a). This process is conditioned by the mechanical characteristics of the material that will allow it to bend and have the necessary flexibility to adapt and maintain the desired initial shape without nails or glue. The shapes and patterns that exist in basketry have been created following the trial and error method, testing natural materials from the area. If the artifact exists, it is because that material has been able to maintain the shape described by the artisan's hands. It did not start with a scientific test of the material properties, elastic limits, or resilience, but rather with ancient techniques involving the immersion of the material into water or heating it, which the artisan knows help to improve the qualities of the material, to bend it more, and maintain its shape for longer.

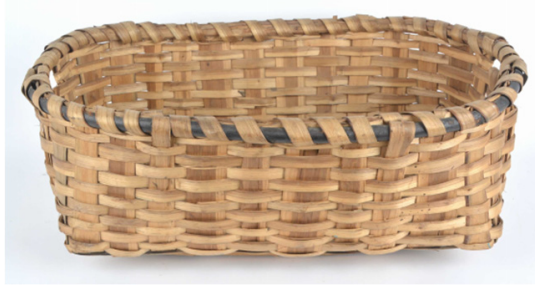

(a)

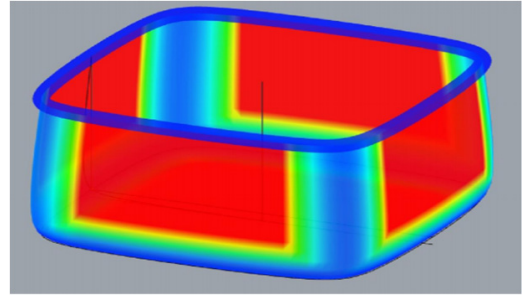

(b)

Figure 6. (a) Basket for transporting fish made by interweaving flat chestnut strips in the Basque Country, Gipuzkoa Provincial Council collection, Registry: GFA-009047-001; (b) Schematic model of the study of the curvatures of the basket with Rhinoceros (source: authors).

Digital 3D modeling software can be used to manage different information, such as the curvature of each point of the weft in the designed geometric shape. If the mechanical properties of that particular material are tested, the 3D model could simulate and optimize a geometry that allows the material to adapt and maintain that shape even with new patterns never before made. Software applications, such as Rhinoceros used in this research, allow coloring the plot based on the minimum radii and maximum curvatures of the designed geometric shape [15]. The colors range from red on the flat faces (most favorable points) 
to dark blue, which reflects the most critical points with the smallest radius of curvature. (Figure 6b).

\section{Materials and Methods}

The research was presented in the context of the global need to promote the use of natural materials for constructions. Taking into account the objectives of the research, a combined method was developed that analyzes both quantitative and qualitative aspects [16]. This section is divided into different aspects, starting with an explanation of the method together with the objectives and techniques, then moving on to the laboratory tests, the samples, and material used, followed by the relevant aspects of the documentary analysis, and ending with the artifact design procedure (3D model) focused on the target.

\subsection{Method}

This study used design science research (DSR) as a methodological approach to design solutions generated by means of 3D models. Within this approach, the utilized research techniques included documentary analyses, case studies, data collection, and trials. DSR is a research approach that focuses on the development and performance of artifacts with the explicit intention of improving the functional performance of processes [17]. In DSR, unlike explanatory scientific research, the objectives of academic research are more pragmatic in nature [18]. Simon argues that DSR is concerned with the design and evaluation of man-made artifacts with the aim of solving real-world problems [19]. DSR is used to find practical applications to common design problems; its application should lead to the expected results [17], and the optimization methods developed are supported by computational tools [19]. If the problems are related to physical objects, solutions can be represented as blueprints, 3D models, or engineering drawings. Problems related to actions can be represented with flowcharts and software solutions [19]. Design theory can include the other forms of design knowledge: constructs, models, methods, and instantiations that convey knowledge [20]. Thus, it is established that design science knowledge is expressed in the form of artifacts-constructs, models, frameworks, architectures, design principles, methods, and/or instantiations and design theories [21]. The authors of [22] suggest that there are two fundamental activities in design science research: constructing a solution and evaluating the solution. The same authors explain that the construction stage is the process of making an artifact for a specific purpose, and the evaluation stage is the process of determining how well the artifact performs in fulfilling its purpose. This is precisely what was done in this research in stages 3,4 , and 5 of the methodological flow described in Figure 7. According to Hevner et al. [23], the construction process is inherently iterative and incremental: the evaluation stage provides essential feedback to the construction phase in terms of the quality of the development process and the solution per se. The design science approach helps to solve the problems of application and relevance that occur in architecture disciplines.

DSR was chosen as the research method for two reasons. First, the research problem is practical, but it also has theoretical relevance, and second, the aim was to develop an artifact as a result. It is also true that DSR expresses a very broad concept. If we were to particularize it for this research, the DSR method could be materialized in a specific denomination that could be called "structured investigative approach". The following is a schematic explanation of the methodology used (Figure 7).

The research comprises five key stages [24]: (i) identification of the problem, (ii) definition of the objectives, (iii) design of the solution, (iv) implementation of the solution, and (v) evaluation of the solution. The three main objectives of this research were: to rediscover the braiding of natural fiber materials for sustainable constructions; to document traditional techniques and confections to preserve existing heritage; and to design, implement, and evaluate new wefts and shapes using 3D digital models. 


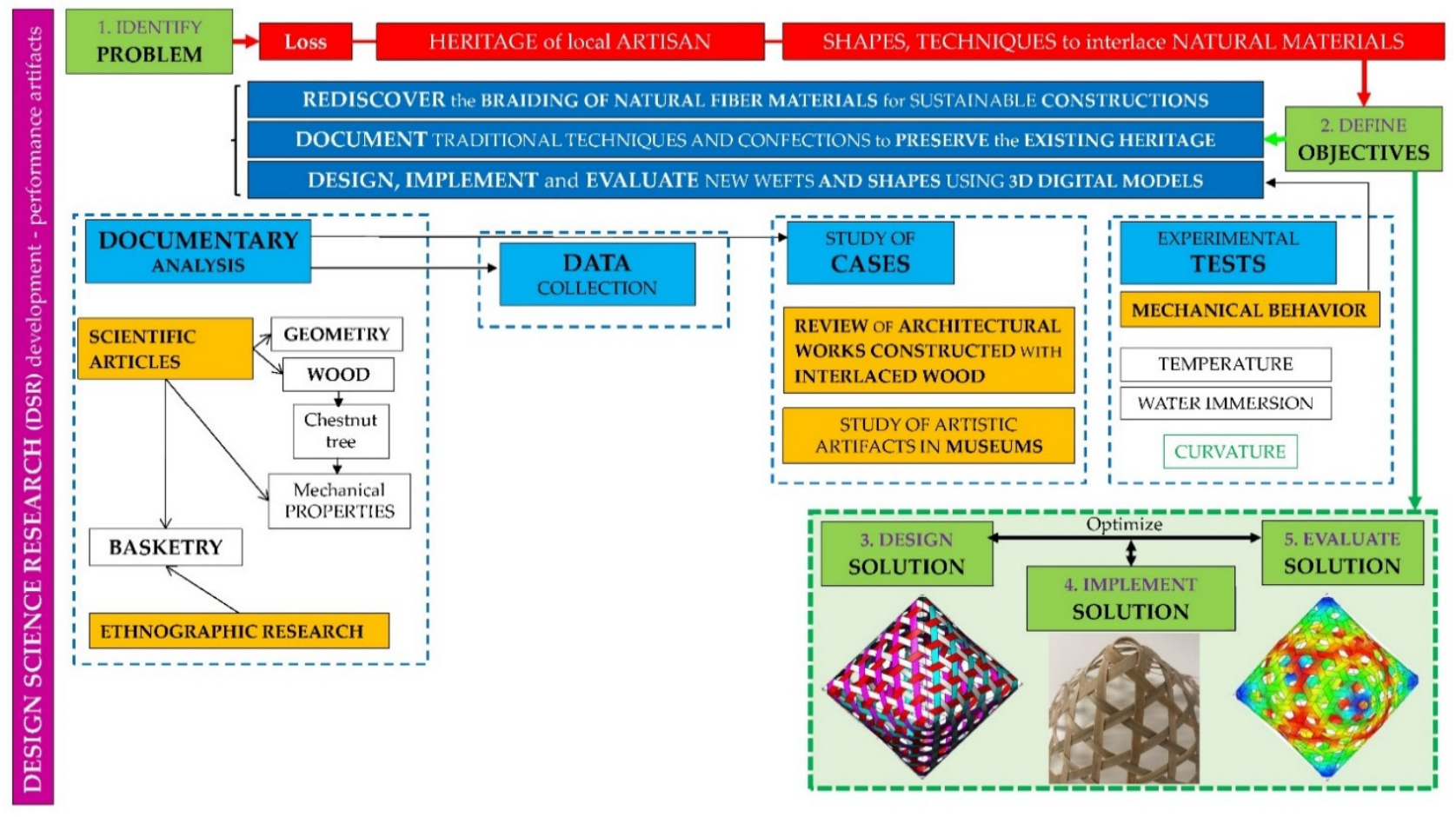

Figure 7. Diagram of the methodology used. Red indicates the problem, dark blue the objectives, light blue the research techniques and dark green the 5 stages of methodology.

\subsection{Documentary Analysis. Qualitative and Quantitative Aspects}

First, an intensive analysis of documents prepared on the subject of study was carried out. Two primary sources were taken into account: first, scientific articles, and second, ethnographic research at a local level, analyzing basketry in Spain, and more particularly in the Basque Country. Multiple data, both qualitative and quantitative, were obtained during this stage. In parallel, a case study was carried out that was divided into two sections: first, international architectural and construction works were analyzed to support the interest in the use of interwoven wood, an aspect that has been developed in Section 2; and second, the different basketry artifacts, built with flat chestnut wood strips contained in the local museum, were studied as samples of the basket heritage preserved in the Basque Country.

Construction with fibers or flat interwoven wooden strips is linked to traditional basketry. In order to understand how this research can help many other places in the world, some qualitative and qualitative findings of interest will be summarized. Weaving techniques associated with basketry have been developed in numerous countries, such as Madagascar, where it is an important traditional activity, providing the only monetary income for many rural households [25]. In Egypt, two Neolithic settlements, Kom K and Kom W, show a well-developed basketry technology [26]. In India, research on rolled basketry is shown [27]. In Indonesia, "crazy interweaving" (anyam gila) is analyzed [28]. This is a type of basketry with a triaxial structure that will be tested in the geometries for the new models designed in this research. In Thailand, each ethnic group has its own identity in the production of bamboo basketry [16]. In the United States, there is recent evidence of African-American basketry in Carolina, Georgia, Alabama, Mississippi, and Florida, whose influence was even felt in Bermuda and the Caicos Islands [29]. Focusing on the California area, there are multiple articles that qualitatively analyze basketry activity $[30,31]$. There is also quantitative research that shows, for example, burning techniques to increase the production of wood stalks for weaving [32]. In South America, there are references to the indigenous society of the Venezuelan Amazon, where basketry acts as a mediator with the westernized world [33]. In Mexico, the meanings of the basketry designs are analyzed, and it can be shown that the flexibility tests on wood have no scientific basis [34]. In 
Ecuador, the collection, management, use, and commercialization of plants are addressed, with special emphasis on basketry. In Europe, in addition to Spain, basketry research can be found in numerous places such as France, Germany and Russia [5]. Furthermore, research carried out in Scotland is of particular interest, as it states that the skills developed in the construction of basketry improve creative thinking and spatial understanding of a person's environment, even improving cognition in people with memory loss or with cerebrovascular accidents [35].

Regarding ancient data about these interlacing techniques, it has been acknowledged that there is evidence that places the origins of these techniques more than 30,000 years ago. Dzudzuana in the Caucasus dates from 30,000 years ago [36]. In the Czech Republic, several findings have been dated to between 24,000 and 29,000 years ago [5]. In Israel, in Ohalo II, the fibers were dated to more than 19,000 years ago [37]. In China, evidence has been found that dates to more than 6000 years ago [5]. In central Sahara, the remains date from the early and middle Holocene [38]. In Spain, there are very old references such as the Neolithic Caves in Albuñol, Granada [39], but probably the oldest references are located in La Draga in Girona, and in Coves del Fem in Tarragona, which are more than 7000 years old $[40,41]$. In the Basque Country, archaeological discoveries in prehistoric caves would establish the existence of basketry made with flat chestnut wood strips from more than 4000 years ago [42].

\subsection{Samples and Material}

Technological advances affect the use of basketry. The use of new materials such as plastic, nylon, or polyester to make utensils that are easy to buy, use and clean is condemning traditional basketry to disappearance [16]. One of the main objectives of this research was to promote the use of this high-quality wood to make interwoven objects, both in the form of baskets or furniture, and as construction elements in buildings (facades, partitions, roofs). Replacing plastics and non-biodegradable materials with biodegradable or natural materials is a worldwide objective, due to the serious damage caused by the former to the environment. In order to continue using these natural materials, it is necessary to preserve this knowledge and these techniques, which in many cases are transmitted from generation to generation through the same family. Most native basket weavers today do not explain the properties of wood in a strict scientific sense. However, they have a sophisticated knowledge of the relationship between environmental conditions, physical disturbances, and the physiology and morphology of their growth [43]. Although the methodology proposed in this article can be developed with many types of wood from anywhere in the world, here it focuses on the local study of " $\mathrm{Km} \mathrm{0"} \mathrm{production.} \mathrm{In} \mathrm{the}$ case of the Basque Country, flat chestnut wood strips are the material used to interlace wood. However, this material is used in a broader context in other parts of the world such as Turkey, England, or Chile. In Spain, Carlos Fontales' book, based on ethnographic research, makes an interesting analysis of basketry [44]. The techniques are classified by the materials used, and the technique developed in the Basque Country is called "cracked wood" due to the technique of obtaining and pretreating the material [44].

In the Basque Country, basketry has been used to build many parts of traditional buildings such as partition walls, closures, and furniture, at least since the Neolithic. Nowadays, this basketry is based mainly on the interweaving of flat chestnut strips [42]. This wood is strong and resistant, perfectly withstanding humidity. For this reason, it has been used for posts or parts that have to be submerged. In extreme humidity conditions this material can corrode the iron nailed into it. However, one of the big problems is that this "know-how" is on the verge of extinction. The knowledge and techniques have been transmitted from generation to generation, and there are not enough documentary records to fully preserve this heritage.

From the natural state of the tree until the constructed interlaced artifact is obtained, the artisan goes through three main phases. These phases would be (i) cutting, (ii) processing until the flat strips are obtained, and (iii), the care and the techniques for the 
construction of the object. With regard to the waste generated by the activity, the production process of the strips is carried out by local producers who are considered as artisans. They are very small-scale operations that are not industrial in nature. They are carried out in the 'caserío' or 'rural house' where the artisans who work also live. Therefore, we are talking about a very small volume of waste that is used to light the fire in the house itself, or to start up the oven. In most cases, the fire is not even connected to a centralized heating or hot water production system of the actual house. Due to the small volume, it is never used for energy production. The chestnut tree used for interlaced basketry is cut at intervals of 6-7 years, when it is about $12-15 \mathrm{~cm}$ in diameter. After that, the cut branches are submerged in a water well for about 3 years. A remarkable characteristic of the chestnut tree that makes it especially interesting for basketry is its ability to resprout from the stump. It can be maintained until approximately 80 years of age. Other natural fibers, such as bamboo, should not be cut during the growing season. To obtain the flat chestnut wood strips, the chestnut tree branches submerged in the water well are extracted and the wood is split into different strips. To facilitate the task, the fire or heat technique is usually applied in the same oven where bread is baked. The wood is boiled thanks to the humidity that is given off by the steam. This phase usually lasts for between 20 and $40 \mathrm{~min}$. After that, the artisan takes out the chestnut wood strips one by one, prying them apart by hand. Each strip is then brushed to make it perfectly smooth. In the last phase, to build the interlaced object, it is recommended to pre-immerse the chestnut wood strips in water. In this way, the material becomes more flexible, making it easier to handle, and helping to maintain the imposed curvature to obtain the desired geometric shape.

As can be seen, the material seems to "work" better when heated and wet, although this does not have a scientific basis. That is what we sought to prove in the test section. First, the material was heated to see how its tensile mechanical properties vary. This entailed proving that by heating the wood, it becomes stiffer and can tear more easily. Second, the chestnut wood strips were moistened to show that the wet material is more flexible and can thus adapt to smaller radii of curvature.

\subsection{Tests}

The tests were developed in two stages: a first experimental stage in the laboratory to analyze the mechanical tensile properties; and a second stage, where flexibility, curvature, and the ability to maintain the imposed shape were tested.

To carry out the tests, flat chestnut wood strips sourced from trees in the area were used. The natural wood strips were made by local artisans in reduced productions. They usually had a variable thickness and width. The working dimensions of the usual strips in 3D models approached a width of $20 \mathrm{~mm}$ and a thickness of approximately $1 \mathrm{~mm}$. The length of the strip and the shape varied depending on the type of test to be performed.

There was no specific standard to test this particular material. For this reason, a bibliographic search was carried out in the main collections of scientific articles (Web of Science, Scopus, and Google Scholar). No article was found that met the conditions of this research, where the mechanical properties of flat wooden strips with immersion treatments in water and heating were analyzed. There were many articles that analyzed the mechanical properties of wood in relation to humidity and temperature, but in most cases, these were tests for structural elements with larger sections. There were also no articles that analyzed the flexibility and the minimum radius of curvature of this type of sample.

\subsubsection{Tensile Strength}

Bearing in mind that artisans immerse the wood in water and subsequently heat the material in an oven, an attempt was made to study the results of this combined effect. On the one hand, analytical tests of the effect of temperature on the variation of mechanical properties of thin-section wooden elements were considered. There were not many references, but some preliminary considerations could be made. Lignocellulosic materials are made up of cellulose, lignin, and hemicellulose. Cellulose is the most abundant component 
and is the structural base. The function of lignin is to bind the fibers. Hemicellulose is the intermediate element between the cellulose and the lignin, and provides resistance. There were also other components. A previous test had analyzed the effect of the processing temperature on the mechanical properties of fiberboards [45]. This was not the same problem, but it was one of the closest experiments found. Here, the effect of the processing temperature on the mechanical properties of chipboard made from fibers originating from the central vein of the banana leaf or coffeewood were evaluated. It was stated that, as the processing temperature increases, there is an increase in the properties of the materials, whereas the degradation of the fibers increases. It was determined that moisture is eliminated between $50{ }^{\circ} \mathrm{C}$ and $100^{\circ} \mathrm{C}$. A first small degradation was observed between $140{ }^{\circ} \mathrm{C}$ and $160^{\circ} \mathrm{C}$, and from $200^{\circ} \mathrm{C}$ this degradation was already considerable. To be able to work with the boards before maximum degradation set in, a range from $160{ }^{\circ} \mathrm{C}$ to $260{ }^{\circ} \mathrm{C}$ was established. It was found that the increase in mechanical properties occurs just after the initial degradation temperature, which indicates that the degradative process favors the activation of the structural components of the fiber. However, when working at extremely high temperatures, despite an improvement of the mechanical properties, the material began to degrade and its appearance was affected.

On the other hand, tests involving immersion in water prior to testing the mechanical properties were considered $[46,47]$. These were once again tests on boards with natural fibers, but they were far from our real sample. As in the test carried out on wicker pieces for basketry, a previous 24-h immersion in water was again established [48].

Taking into account these previous tests, several $200 \mathrm{~mm} \times 20 \mathrm{~mm} \times 1 \mathrm{~mm}$ samples, prepared with a dogbone geometry, were tested according to tensile test standards [49]. Initial humidity was measured with a Brennenstuhl hygrometer that allows the measurement of a moisture level between $5 \%$ and $50 \%$. With a relative humidity $(\mathrm{RH})$ of the air of $45 \%$, and at a temperature of $21.5^{\circ} \mathrm{C}$, the wood of the test sample had a surface humidity of $6 \%$. This would be the humidity of the flat strips when starting to build the real models from the 3D models. First, the samples were tested in their natural state (6\% humidity). Second, samples submerged in water for $24 \mathrm{~h}$ and heated to $160{ }^{\circ} \mathrm{C}$ were tested. Next, natural state samples heated to $160{ }^{\circ} \mathrm{C}$ were tested. The samples were heated in a Selecta laboratory oven with a temperature range of $0{ }^{\circ} \mathrm{C}$ to $250{ }^{\circ} \mathrm{C}$. The samples were heated for $10 \mathrm{~min}$ according to the previous references studied [45]. The tensile test was carried out in an Instrom Universal Testing Machine, model 4206, which had a load cell of $100 \mathrm{KN}$ at an advance speed of $5 \mathrm{~mm} / \mathrm{min}$.

\subsubsection{Flexibility and Curvature Tests}

The vegetable fibers used in basketry are not totally malleable. Although all of them have greater or lesser flexibility, they always pose resistance. They have the natural tendency to "return to their straight state", to the direction of organic growth. The aim of this test was to prove that immersion of the flat chestnut wood strips in water before constructing the woven basket artifact allows the artisan to work with a more flexible material. This has a direct impact on the achievable radius of curvature.

As in the previous case, there were no bibliographic references in scientific publications that described a standardized procedure to measure the ability to naturally bend the moistened material. There were tests that analyzed the curvature capacity of fabrics [50], and others that studied the minimum radius of curvature for bamboo strips with different cuts [51]. There were also tests that analyzed the ability of wicker to bend [48]. Taking these articles as a reference, a test was carried out with flat chestnut wood strips. Two types of sample were prepared. One was the same as for the previous test, i.e., $200 \mathrm{~mm} \times 20 \mathrm{~mm} \times 1 \mathrm{~mm}$, and the other was rectangular, $100 \mathrm{~mm} \times 20 \mathrm{~mm} \times 1 \mathrm{~mm}$. Half of the samples were tested naturally, and the other half were tested after being immersed in water for $24 \mathrm{~h}$. After several preliminary tests, different strips of the two types of samples were wound on a cylinder with radius $\rho=10 \mathrm{~mm}$ and, on another cylinder with radius $\rho=12 \mathrm{~mm}$. First, an attempt was made to roll the strips naturally with $6 \%$ humidity, 
and then the wet strips were rolled. Those that were able to adapt to the shape without breaking were kept for 12 and $24 \mathrm{~h}$ to verify their ability to maintain their shape after being released from the cylinder. With this, it was possible to test whether the wet strips were more flexible, as well as what type of samples better maintained the imposed shape.

\subsection{D Model-Based Solution}

The ultimate goal of the proposed methodology was to obtain artifacts with interwoven wooden strips to respond to the research problem, meeting the objectives set. On the one hand, it was about being able to design, implement, and evaluate new geometric shapes interwoven with new wefts, and on the other, to document the local basketry heritage techniques in 3D digital models, so that these artifacts could be replicated in the future. One must remember that nowadays, interwoven constructions cannot be replicated if how they are built is unknown. The techniques to interweave these constructions have been transmitted from generation to generation by imitation. There are no construction or assembly drawings. If there are proposals for new designs, the basket makers analyze them based on the models they have made throughout their lives. Using their family heritage, they will try to "imitate" this new shape. The result has to be adapted to the artisan. The aim was for the 3D digital model to enable us to test new wefts in new ways [52]. The model would allow foreseeing if the radius of curvature of the designed geometry could be developed with the mechanical characteristics of that material. These models, solved using Rhinoceros software, were to be implemented in scale models. The construction difficulty would be evaluated, and the initial model optimized so that it could be replicated by other people. Three-dimensional digital models can be viewed and shared online on free web platforms such as Sketchfab [53]. These models may have additional embedded information, such as photos, assembly videos, and all kinds of documents. In addition, they can be viewed with virtual reality eyewear.

In order to generate new designs never made before, Grasshopper can be used. This is a plug-in that runs within the Rhinoceros software. It is a visual programming language where artifacts are created by dragging components into the work area (Figure 8).

The Rhinoceros software permits obtaining the radius of curvature at each point in the model. This resource enables visualization, through colors, of the critical points where the radius of curvature will not be absorbed by the material. Red indicates areas where the curvature is zero, and therefore any material is appropriate. The color changes to yellow, green, light blue, and dark blue where there is maximum curvature, marking the most critical areas for the material. Depending on the mechanical characteristics of the type of material, this shape may or may not be executed. Conversely, if forcing the execution of a shape is desired, the appropriate material would be chosen so that it can be bent with those radii of curvature (Figure 9).

Our research case was more complex than that of wicker weaving. The flat strips allowed infinite wefts with 2, 3 or more strips [54]. First, different wefts had to be parameterized with Grasshopper, and then an initial evaluation of the curvature of those wefts had to be made for the chosen material (Figure 10).

The most critical part occurred when the weft had to adapt to the desired geometric shape. With Grasshopper it was possible to limit the curvatures so that the shape adapted to the mechanical characteristics of the material. 

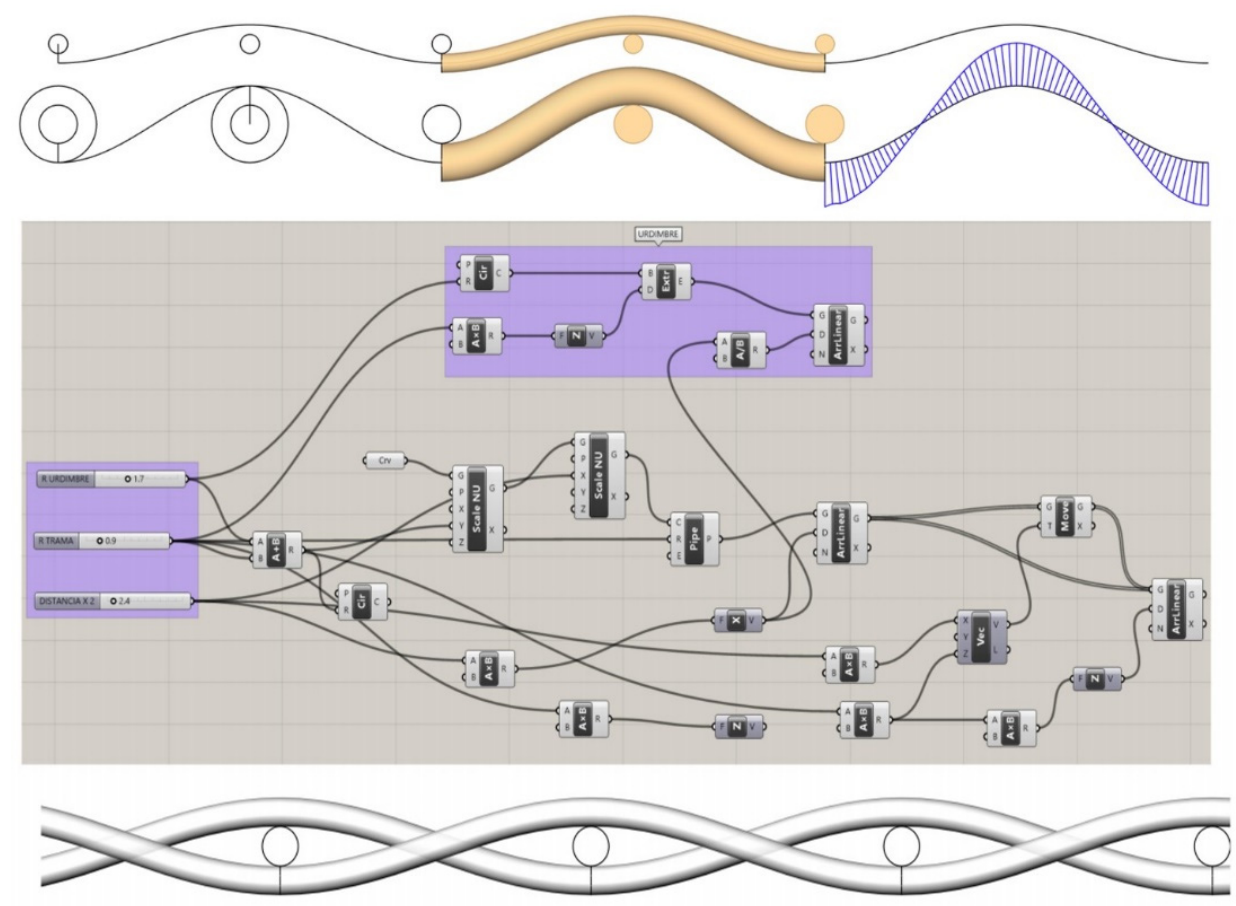

Figure 8. Example of parametrization for artifacts interwoven with wicker.

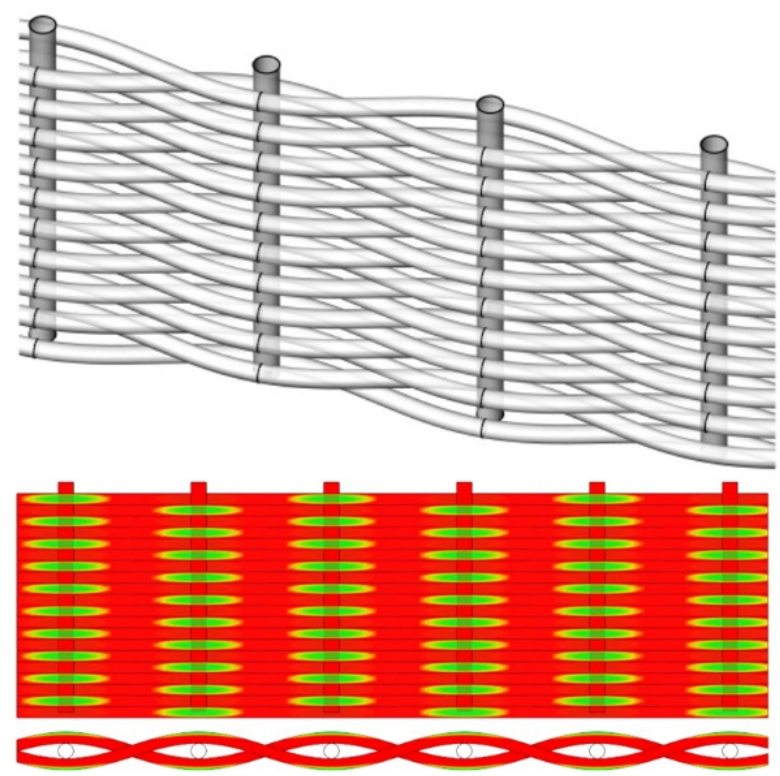

(a)

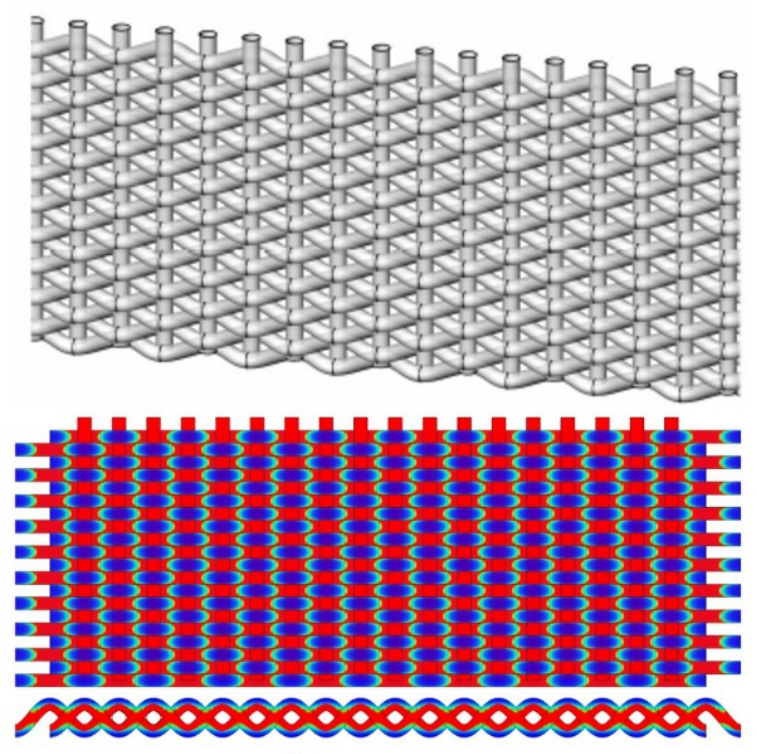

(b)

Figure 9. (a) In the parameterized model, some curves have been developed for the wood; (b) If the curvature is maximum (dark blue), the artifact would have to be made with a material of maximum flexibility, such as a synthetic material. 


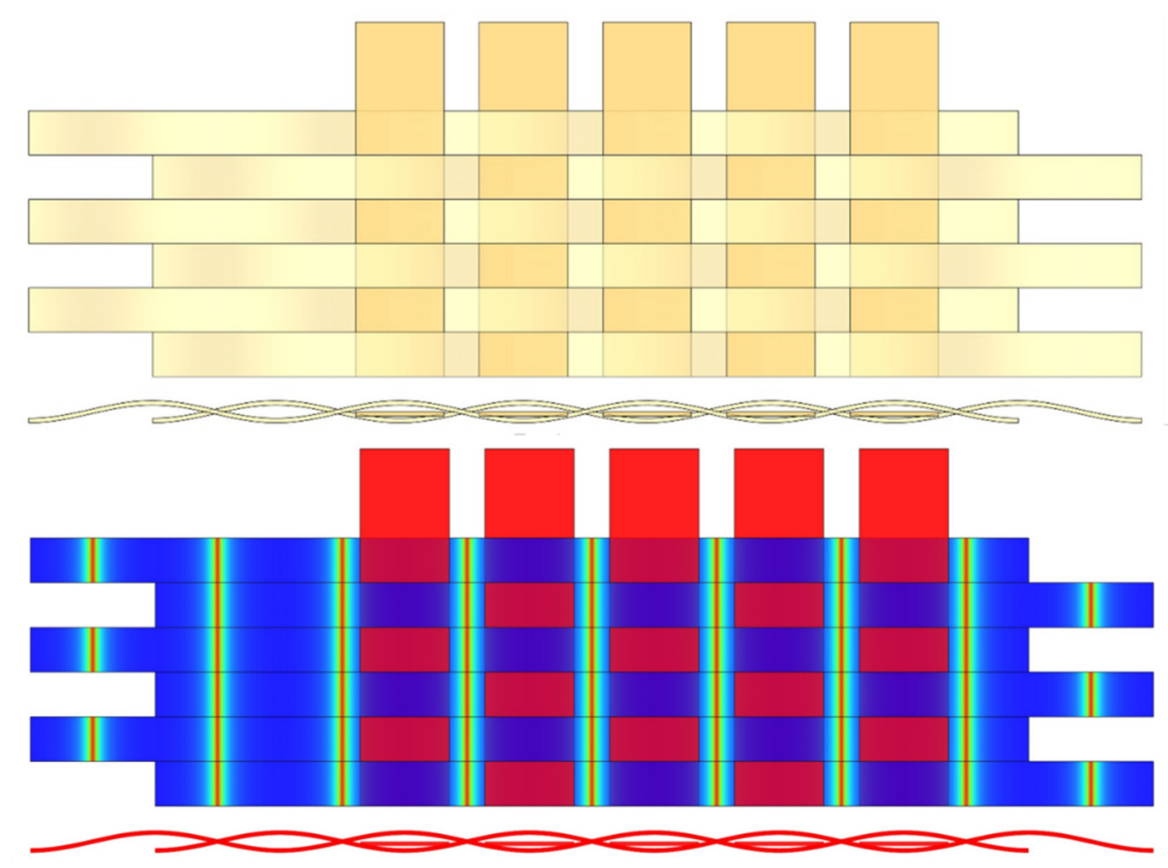

Figure 10. Example of analysis of curvatures of flat interwoven chestnut strips before being curved to build a geometric shape.

\section{Results and Discussion}

The findings from the documentary analysis and data collection were used to complete the information in different parts of the article. The results were divided into two sections; one to present the test results, and the other, to present the results of the model design oriented to the final objectives of the research. As there are several results sections, they are discussed in the order presented.

\subsection{Tests}

\subsubsection{Tensile Strength}

Quantitative findings for the chestnut tree have been included in the methodological data collection section. The Center for Innovation in Vocational Training, dependent on the Basque Government, has characterized the chestnut tree [55]. The results are divided into two blocks:
a. Physical properties

- Apparent density at $12 \%$ humidity: $590 \mathrm{~kg} / \mathrm{m}^{3}$, medium light

- Volumetric contraction coefficient: $0.39 \%$

- Hardness (Chaláis-Meudon): 2.5 semi-soft

- Tendency to curve: Small. Persistent wood.

\section{b. Mechanical properties}

- Flexural strength: $710 \mathrm{~kg} / \mathrm{cm}^{2}$

- Resistance to compression: $460 \mathrm{~kg} / \mathrm{cm}^{2}$

- Tensile strength: $1280 \mathrm{~kg} / \mathrm{cm}^{2}$

- Modulus of elasticity: $100,000 \mathrm{~kg} / \mathrm{cm}^{2}$

These values were always used as reference but could not be considered to analyze a specific handmade material. The specific samples that were used to design and create the artifacts or mockups in 3D needed to be tested. Focusing on the experiment carried out in the laboratory, the three types of tests performed should be remembered: (i) the flat strip directly without treatment, expressed with reference "NS"; (ii) immersed in water for $24 \mathrm{~h}$ and later heated in an oven for $10 \mathrm{~min}$ at $160^{\circ} \mathrm{C}$, expressed with the reference "MC"; (iii) the natural flat strip heated in an oven for $10 \mathrm{~min}$ at $160^{\circ} \mathrm{C}$, expressed with the reference 
"NC". The following were determined: Young's elastic modulus E, from the slope of the tangent line in the initial zone of the stress-strain curve; the maximum resistance, $\sigma$; and the deformation at break, $\varepsilon_{\mathrm{z}}$. In each type of test, 20 standardized wooden dogbone-shaped test specimens of each system were tested [56], taking into account the data defined in the methodology.

Figure 11 shows some stress-strain curves for the three systems, as an example, where the different behaviors of the flat strips can be seen. An attempt was made to find the representative value in each type of system. Figure 11a shows representative diagrams of the NS specimens, Figure 11b diagrams of the NC specimens, and Figure 11c diagrams of the MC specimens.

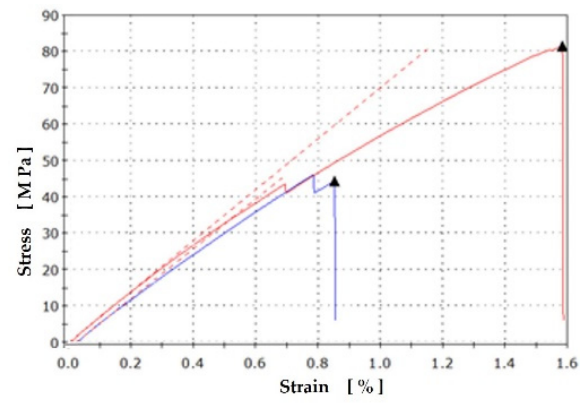

(a)

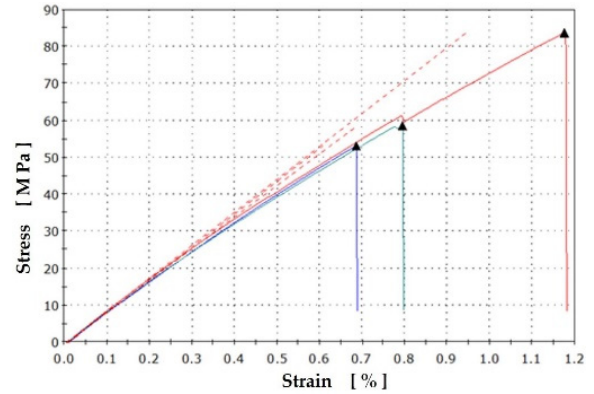

(b)

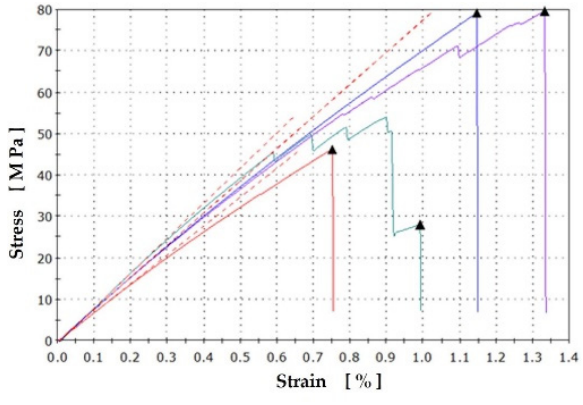

(c)

Figure 11. Stress vs. strain diagrams of the systems: (a) NS; (b) MC; (c) NC.

In Table 1 the mean and standard deviation of key data are summarized.

Table 1. Values of E, $\sigma$, and $\varepsilon_{z}$ of the three systems studied.

\begin{tabular}{|c|c|c|c|}
\hline Specimens & $\begin{array}{c}\text { Young's Modulus E } \\
\text { (MPa) }\end{array}$ & $\begin{array}{c}\text { Maximum } \\
\text { Resistance } \sigma(\mathrm{MPa})\end{array}$ & $\begin{array}{c}\text { Deformation at } \\
\text { Break } \varepsilon_{\mathrm{z}}(\%)\end{array}$ \\
\hline NS & $7096 \pm 167$ & $\begin{array}{l}46.47 \pm 5.85 \\
89.14 \pm 7.81\end{array}$ & $\begin{array}{l}0.73 \pm 0.12 \\
2.11 \pm 0.73\end{array}$ \\
\hline $\mathrm{MC}$ & $7738 \pm 605$ & $\begin{array}{l}51.20 \pm 5.56 \\
79.29 \pm 4.02\end{array}$ & $\begin{array}{l}0.87 \pm 0.17 \\
1.24 \pm 0.15\end{array}$ \\
\hline $\mathrm{NC}$ & $8740 \pm 189$ & $\begin{array}{l}52.87 \pm 5.90 \\
83.71 \pm 3.19\end{array}$ & $\begin{array}{l}1.17 \pm 0.12 \\
1.66 \pm 0.11\end{array}$ \\
\hline
\end{tabular}

As can be seen, the rigidity was similar in both flat strips, and this behavior was repeated in the three systems studied. However, in the maximum resistance and in the deformation at break (marked in the diagram with arrows) tests, it is observed that one batch of flat strips was significantly superior to the others. Thus, in Table 1, two results are presented for $\sigma$ and $\varepsilon_{z}$ for each system. Some of the samples had given values in one range, and others in a different range. This behavior could be attributed to the fact that there were two types of flat chestnut wood strips. Small-scale local production and processing techniques without standardized procedures were behind this difference. One option was for the strips to come from two different chestnut trees. Another was that a flat strip was more central and the other more peripheral in the $12 \mathrm{~cm}$ trunk of the chestnut tree that the artisans split in the process. There have been tests carried out with bamboo that corroborate this difference depending on where strips are located in the cut [51]. This information cannot be verified a posteriori due to the procedures of the artisanal process. This is considered one of the limitations of the research in this section. However, this different behavior could also be attributed to the way the specimens broke. Some specimens appeared to have broken within, or very close to, the grip section, as can be seen in Figure 12, which shows the way the strips broke according to the treatment. Figure 12a 
shows some NS specimens after the test, Figure 12b, some NC specimens, and Figure 12c, some MC specimens.

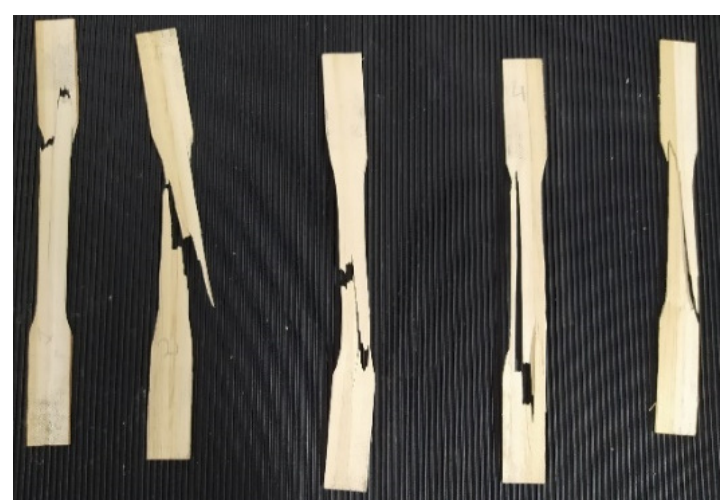

(a)

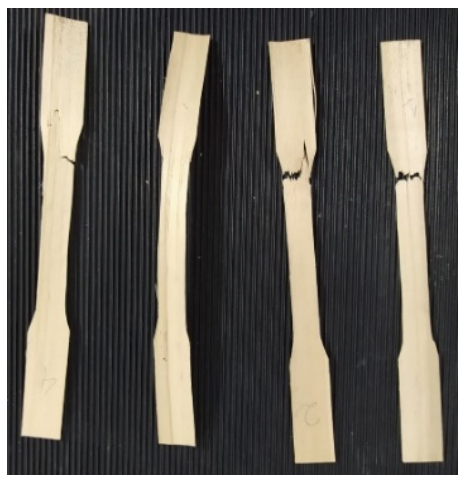

(b)

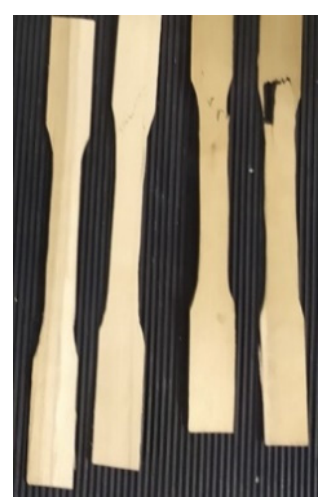

(c)

Figure 12. Example of breakage of some test specimens of the system: (a) NS system; (b) MC system; (c) NC system.

Regarding the effect of the treatments on the flat strips, it can be observed how heating to $160{ }^{\circ} \mathrm{C}$ produced an increase in elastic modulus $\mathrm{E}$ of the strips, which was even more noticeable when the strips had not been previously immersed in water. In the context of data scatter, it can be said that, in the strips directly heated to $160{ }^{\circ} \mathrm{C}$, the $\mathrm{E}$ modulus increased by about $20 \%$, whereas for those that had been immersed in water for $24 \mathrm{~h}$, this increase was around $10 \%$. This behavior can be attributed to the chemical composition of the wood, basically cellulose and lignin, hygroscopic biopolymers that absorb a large amount of water, with the latter acting as a plasticizer. Thus, when it dries, the water is removed, and the material becomes stiffer. On the other hand, in terms of maximum resistance and deformation at break, a slight increase in resistance and deformation was observed with the treatments to the strips that initially had lower resistance and deformation. It is worth mentioning that the way the strips broke differed according to the treatments. As can be seen in Figure 12a, the NS test specimens broke longitudinally along their length after generating a first initial crack. This is also observed in the diagram of Figure 11a, where the step produced after this first break is seen. On the other hand, the NC test specimens broke transversely to their length, directly, without intermediate pre-cracking. This can be seen in Figure 11b, where the intermediate step is not observed. However, the MC test specimens again showed a similar behavior to the NS. This behavior is again attributed to the presence of water in the biopolymers, which was higher in the NS system (with initial humidity of $6 \%$ ), followed by the MC system, and much lower in the NC system.

Therefore, if the flat strips were immersed in water, they were more flexible because the water acted as a plasticizer. If they were heated, they dried out, and therefore their rigidity increased. This can be interesting when the artisan tears the strips from the trunk of the chestnut tree. If heated without pre-immersion, they burn, and their appearance makes them undesirable for modeling.

\subsubsection{Flexibility and Curvature Tests}

In order to carry out the final flexibility and curvature tests on the flat chestnut wood strips, preliminary tests were carried out to determine the critical radii at which the material could be bent. For this purpose, two aluminum cylinders were prepared, so that the humidity of the strips would not affect them. The radii of the cylinders finally chosen were $1 \mathrm{~cm}$ and $1.2 \mathrm{~cm}$. The flat chestnut strips were rolled by hand, as carried out by artisans. The strips that could be rolled without breaking were kept on the cylinder with transparent adhesive tape. This adhesive tape was removed after $12 \mathrm{~h}$ in some cases and after $24 \mathrm{~h}$ in others. As mentioned, two types of flat strips were used. Type 1 was $200 \mathrm{~mm} \times 20 \mathrm{~mm} \times 1 \mathrm{~mm}$, the same as for the tensile test, and type 2 had a 
$100 \mathrm{~mm} \times 20 \mathrm{~mm} \times 1 \mathrm{~mm}$ rectangular shape, so the fibers were shorter and more difficult to roll. First, an attempt was made to wind the untreated type 1 flat strip at $45^{\circ}$ onto a $1 \mathrm{~cm}$ radius cylinder. It was found that it could not be adapted to the surface. The same type of strip, untreated, could be wound onto a $1.2 \mathrm{~cm}$ radius cylinder, but it broke. It was not fixed to the cylinder, but the curved shape that it instantly adopted was largely maintained from the very first moment. After $24 \mathrm{~h}$, it maintained practically the same shape because its humidity content had not changed (Figure 13a). The same type of strip immersed in water for $24 \mathrm{~h}$ adapted to the curvature of the $1 \mathrm{~cm}$ radius cylinder, but it also broke. It was not fixed to the cylinder either, but when wet, it practically recovered its original state in seconds. When wet, it was more flexible but recovered its shape sooner (Figure 13b).

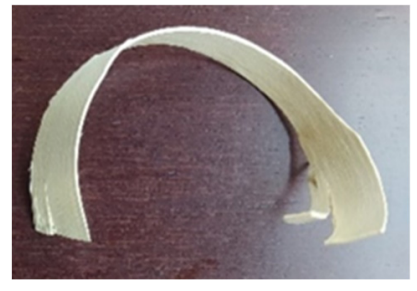

(a)

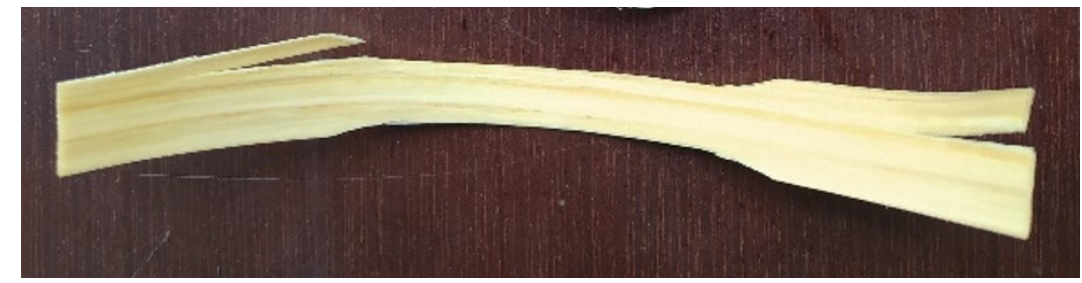

(b)

Figure 13. Tests of: (a) Winding natural strip type 1 onto the $1.2 \mathrm{~cm}$ radius cylinder without fixing; (b) Winding wet strip type 1 for $24 \mathrm{~h}$ onto the $1.2 \mathrm{~cm}$ radius cylinder without fixing.

The type 1 strip, pre-immersed in water for $24 \mathrm{~h}$, could be wound onto the $1.2 \mathrm{~cm}$ radius cylinder without breaking. It remained fixed for $24 \mathrm{~h}$. When released, it maintained a spiral shape, although with a larger curvature than the radius of the cylinder to which it was attached (Figure 14a). Using type 2 strips, the wet strip was adapted and attached to the $1 \mathrm{~cm}$ radius cylinder. It was decided to release it after $12 \mathrm{~h}$, observing that it lost the $1 \mathrm{~cm}$ radius of curvature, but maintained a pronounced curvature. After $24 \mathrm{~h}$, it maintained the same shape as after $12 \mathrm{~h}$ (Figure 14b). The type 2 untreated strip wound onto the $1 \mathrm{~cm}$ cylinder did not adapt well, breaking in the center and on the side of one end. When removed after $24 \mathrm{~h}$, it initially lost its shape but maintained a greater curvature than the one previously immersed in water (Figure 14c).

Finally, an $80 \mathrm{~cm}$ strip was immersed for $24 \mathrm{~h}$ and wound onto a $1 \mathrm{~cm}$ radius cylinder. It was fixed until it was completely dry (reaching the initial humidity of the untreated strips). In this case, the flat strip acquired the shape of the cylinder practically $100 \%$, maintaining it over time (Figure 15).

With this test, it could be proved that when a flat chestnut wood strip is immersed in water, it is more flexible and adapts to smaller radii of curvature, and can easily be wound onto a $1 \mathrm{~cm}$ radius. However, when released from the cylinder, if it had not lost all the humidity added by immersing it in water, and would recover its original shape to a greater or lesser extent. If the flat strips were untreated, it was difficult for them to adapt to a $1 \mathrm{~cm}$ radius of curvature, and they broke in all cases. When wound onto a $1.2 \mathrm{~cm}$ radius cylinder they did not usually break, although it was difficult to adapt them to the shape. However, when released, they maintained their acquired curvature better. If a flat strip was wound onto a $1 \mathrm{~cm}$ radius cylinder and left to dry, it would practically keep the wound shape, even when peeled off. 


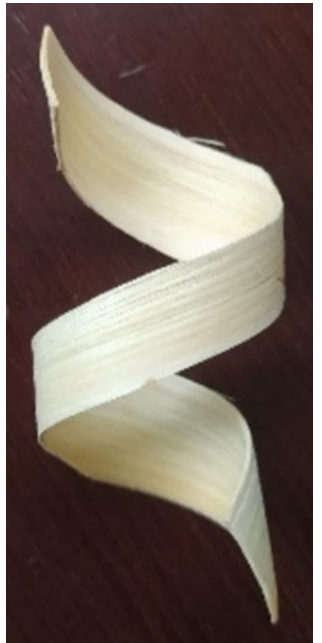

(a)

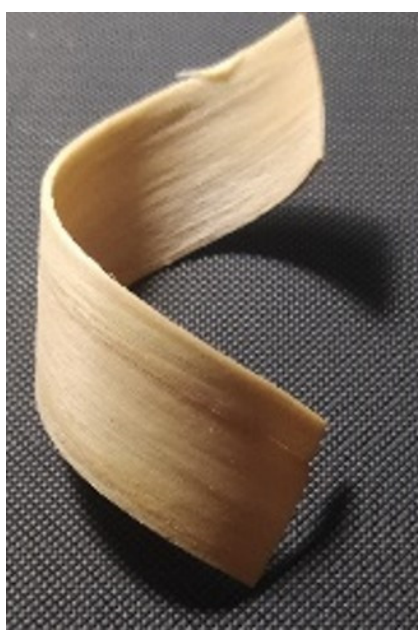

(b)

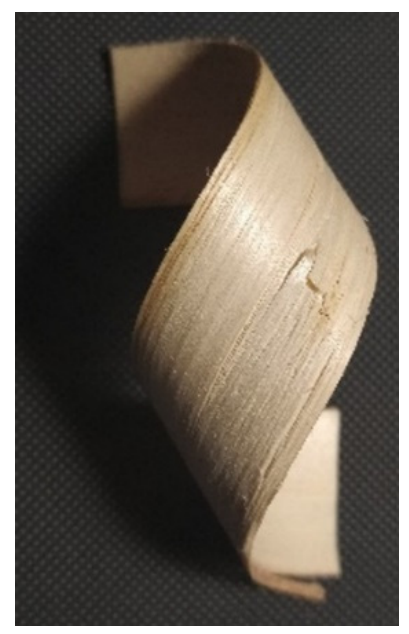

(c)

Figure 14. Tests of: (a) Winding type 1 strip immersed for $24 \mathrm{~h}$ onto a $1.2 \mathrm{~cm}$ radius cylinder for $24 \mathrm{~h}$; (b) Winding type 2 strip immersed for $24 \mathrm{~h}$ onto a $1 \mathrm{~cm}$ radius cylinder, fixed for $12 \mathrm{~h}$. (c) Winding type 2 untreated strip onto a $1 \mathrm{~cm}$ radius cylinder, fixed for $24 \mathrm{~h}$.

\section{$(1904(141141111111111) 1$}

Figure $15.80 \mathrm{~cm}$ strip immersed for $24 \mathrm{~h}$ and wound onto a $1 \mathrm{~cm}$ radius cylinder until dry.

\subsection{D Models}

Considering the mechanical characteristics of the material, the final result aimed at by the objective of the research was obtained. The aim was to obtain artifacts with flat interlaced strips of wood by designing, implementing, and evaluating new geometric shapes with new wefts by means of 3D digital models. Young's modulus and the roll up test made it possible to set the minimum radius of curvature to which this material can be subjected. New wefts were created through parametrization, which were implemented in new geometric shapes that traditional basketry has not yet explored, and an evaluation of the radius of curvature of each flat strip was carried out to check if the artifact could be built. After that, the mockup was made and the final digital model optimized. Initially, new wefts were created with 2 and 3 flat strips. The possibilities are endless with Grasshopper (Figure 16).

Once the wefts had been designed and rendered in a flat development, the new geometric shape was designed. The weft, which had not been used by local artisans, had to be adapted to new shapes never before constructed in local basketry. In many cases, these were simple geometric shapes, but ones that the artisans had not been able to create because they did not have previous models to imitate. Perfectly designed, evaluated, and optimized 3D digital models can serve as a basis for the artisan to try to imitate that digital artifact with real natural material. The cone is one of the most relevant figures in basketry. Through the union of multiple cones, many new shapes can be explored. The ability of the $3 \mathrm{D}$ digital model to detect conflictive points where the natural material will be exposed to a radius of curvature that it will not be able to absorb, is presented. It begins with a simple weft, raising a cone with a rectangular weft interlacing strips in two directions. The software colors the surface based on the curvature. The red surfaces are the least critical (strip in a flat state), and the dark blue ones (near the vertex) are the ones with the smallest radius of curvature (Figure 17). 


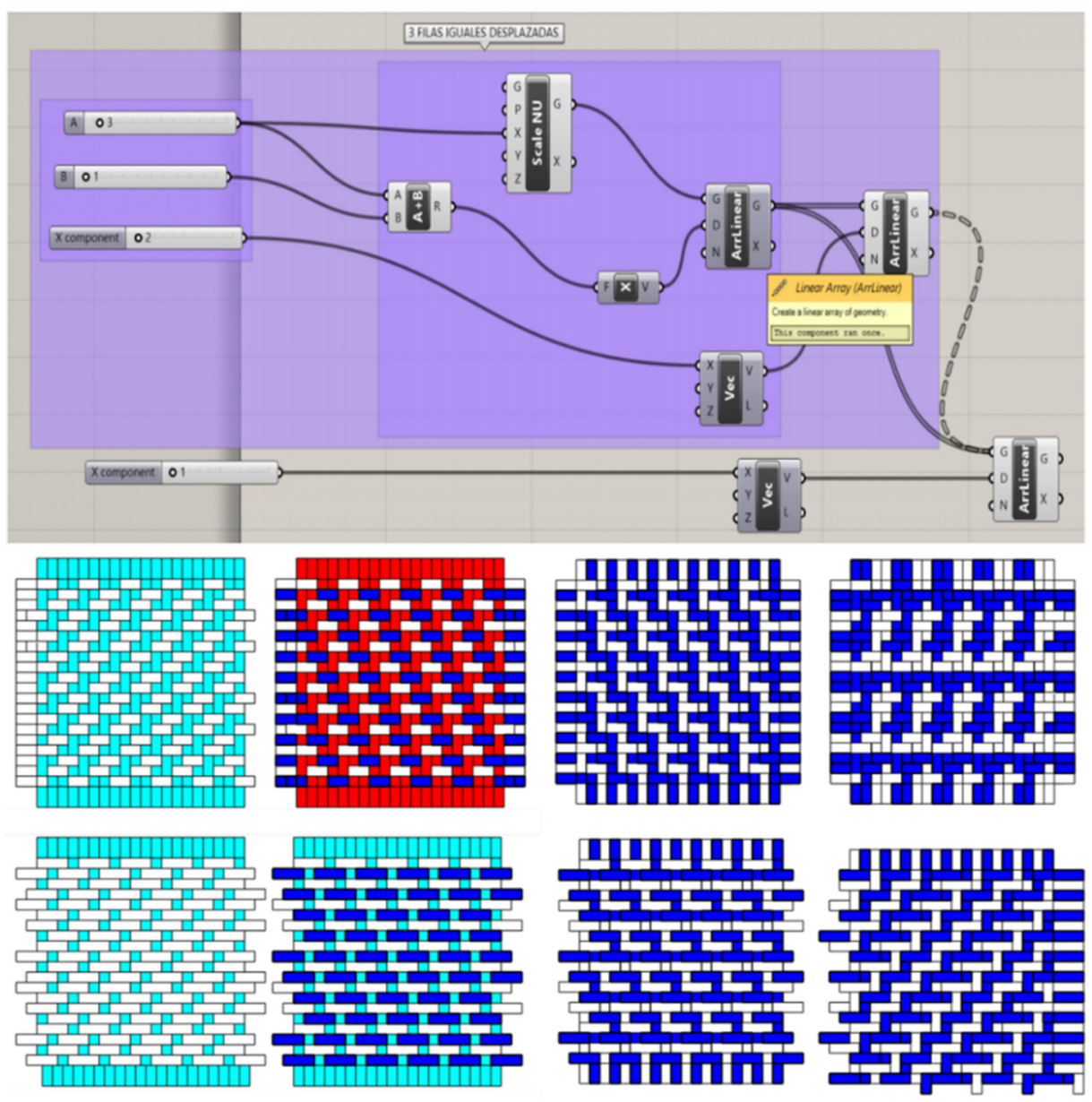

Figure 16. Parametrization with Grasshopper, and new interwoven patterns created.
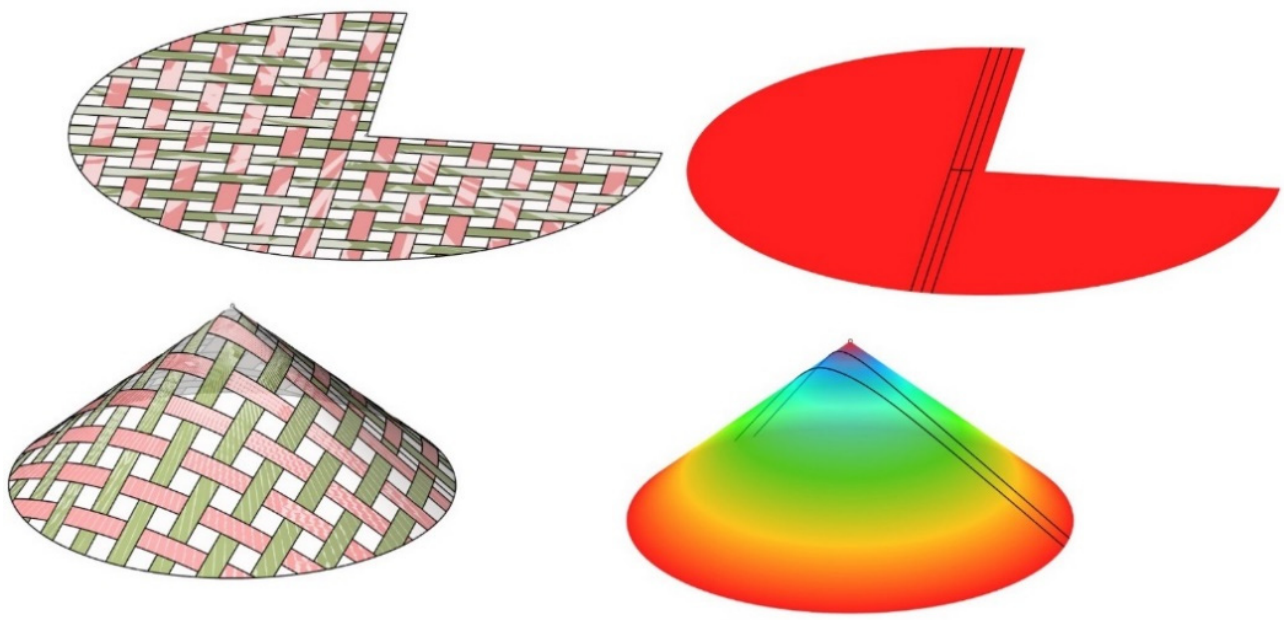

Figure 17. Cone with rectangular weft. Curvatures reflected with a color code.

By isolating one of the most critical strips of the model, the radius of curvature at each point of the central line of the flat strip to be curved can be obtained (Figure 18). 


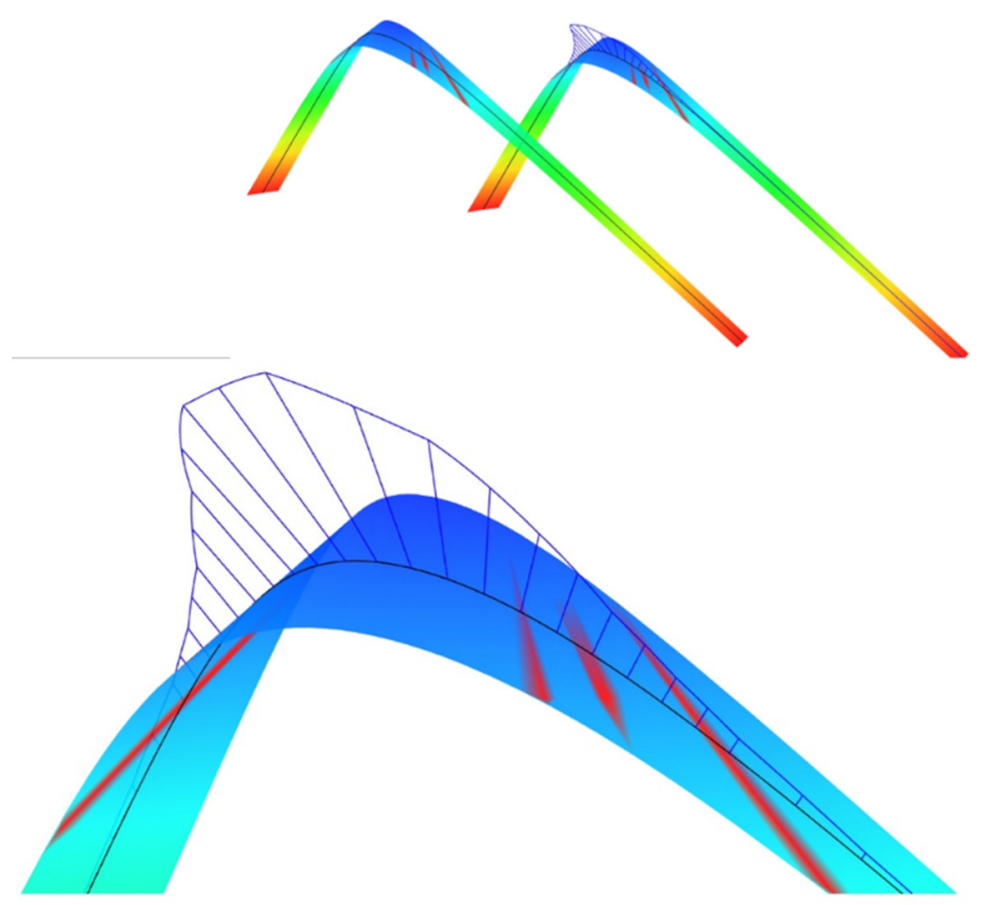

Figure 18. Flat strips with more conflicting radii of curvature. Curvatures reflected with lines perpendicular to the center line of the flat strip. The most critical part shows a dark blue color.

If the procedure is understood, the result can become more complex. Another example made by means of the Kagome weft composed of 3 flat strips is presented. Different cones are designed, which will serve as the basis for completing a compound geometry (Figure 19).
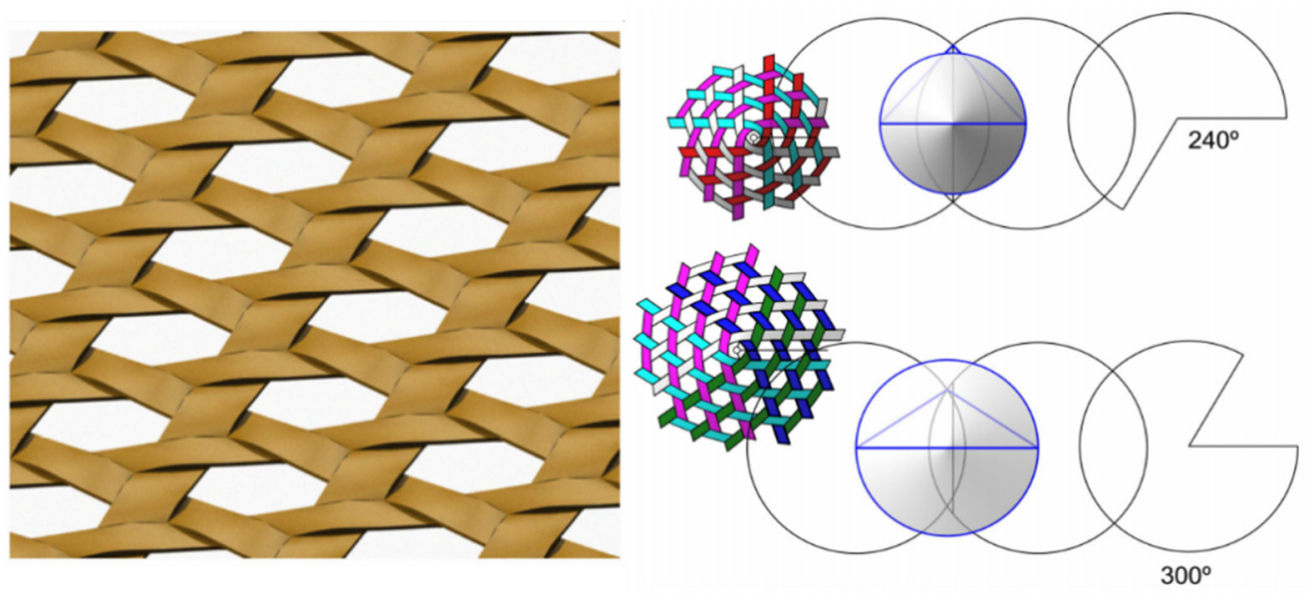

Figure 19. Kagome interweaving, applied to different cone designs.

With different cones, complex geometric shapes can be created, such as the octahedron with Kagome weft. First of all, the geometric shape was designed with three strips that are represented by different colors (white, red, and light blue). After that, the curvatures of the flat strips can be evaluated, to detect if any chestnut strip would not be able to bend with that radius. The most favorable points appear in red and the most conflictive in dark blue (Figure 20). 

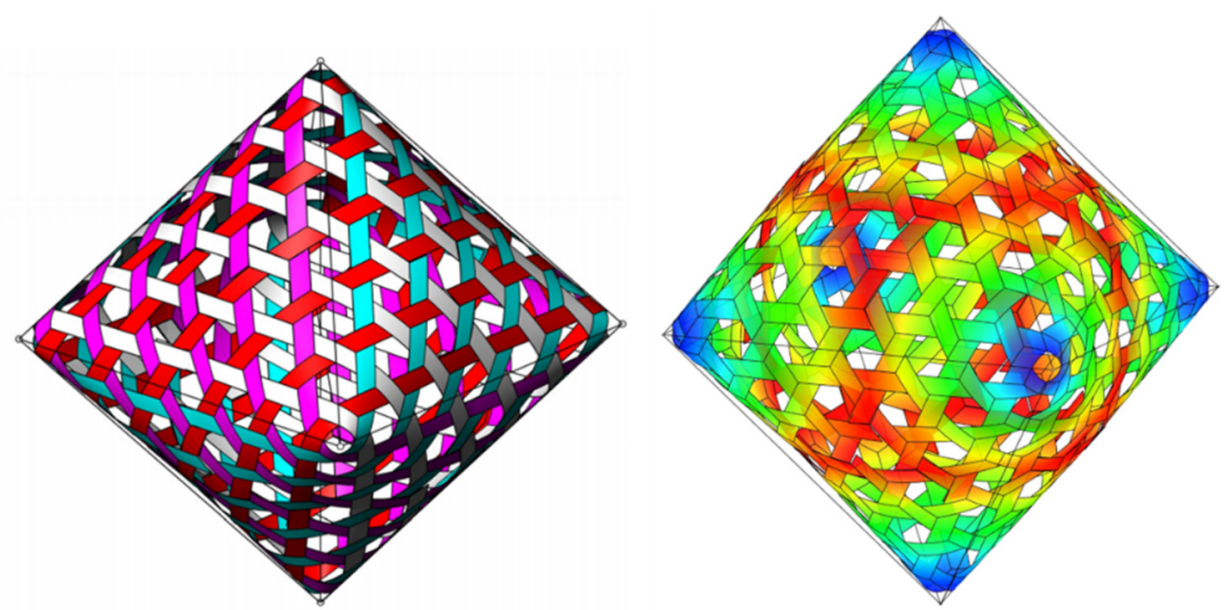

Figure 20. Octahedron Kagome design, and evaluation of curvatures for geometry optimization.

The shape can be made more complex by applying a more or less simple weft (Figure 21). In any case, the software allows the evaluation of curvatures. If the material was not able to bend at any point due to its mechanical properties, there was a choice of two solutions. The first, carried out with Grasshopper, showed where the maximum curvature could be limited to a radius of $1 \mathrm{~cm}$, taking into account the results of Section 5.1.2. This implies that the initially designed shape would adapt to that condition. The second would be to scale the designed artifact, so that the radius of curvature increases. It would also be possible to implement it or build it with another type of wood, which, although not the objective of this research, is common practice in real constructions. Future lines of research can tackle these aspects.

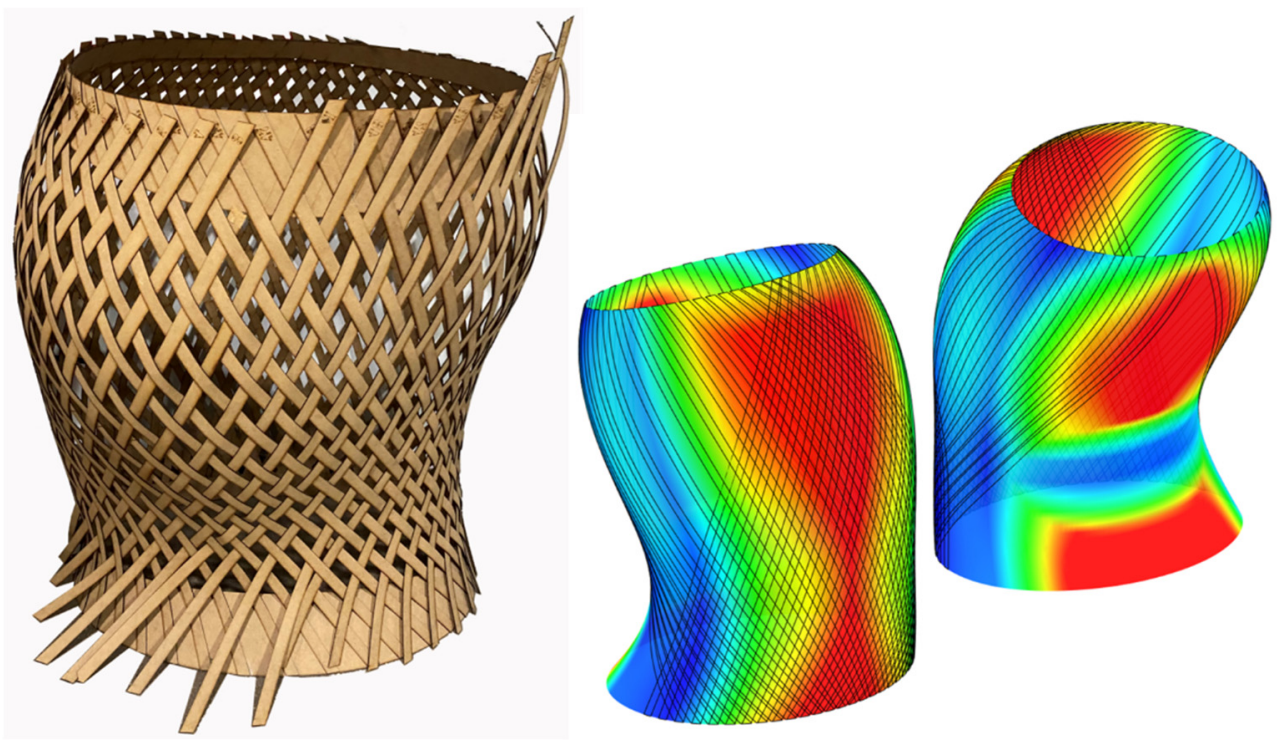

Figure 21. Complex shape built with $2 \mathrm{~mm}$ thick medium density flat wooden strips.

\section{Conclusions}

The aim of this research was to promote the use of materials for construction. It focused on constructions made by interlacing flat strips of wood, influencing aspects such as sustainability and environmental improvement. It was specific for the study of locally produced chestnut trees in the Basque Country, in northern Spain. However, the proposed methodology can be replicated anywhere in the world, adapting it to locally produced wood in each area. Traditional basketry techniques must be mastered to build flat strips of wood by interweaving. The problem is that in many parts of the world, these techniques are 
transmitted from generation to generation within very specific families, and this knowledge is being lost. The production and handling procedures have no scientific basis and are difficult to replicate. Constructed artifacts are built by imitation, seeing how other previous models are built. The design options are becoming fewer and far between, and no new shapes are being created. Given these problems, this research will allow us to benefit from the following advances or advantages: On the one hand, the proposed methodology has made it possible to test, by means of digital 3D modeling software, new models that local artisans had not been able to design or manufacture with existing ancestral techniques. On the other hand, all the information on the production process of the material and the making of the interwoven objects, which is currently stored in the minds of the artisans, will no longer be at risk of extinction. This is possible because 3D digital models have the capacity to include both existing information and the advances developed in this research, making them a perfect medium for storing knowledge, evolving and improving it, passing it on to future generations, and thus preserving this important heritage. Furthermore, this type of research, which scientifically and empirically analyzes the improvements or disadvantages of wetting and/or heating wood with specific characteristics, will provide artisans with objective data on the characteristics of their production. It is significant, for instance, that in the same batch of supplied material, the existence of two very marked groups, with very different resistant characteristics, was detected by means of traction tests. This could lead to suppliers of the material having their products more closely controlled.

With the methodology proposed in this research, it is possible to create new artifacts with new geometries using new interweaving patterns, based on scientific analyses that identify the mechanical properties of the material. Digital software, such as Rhinoceros, was used, facilitating the design, implementation, and preliminary evaluation of the results so that the material will be capable of bending at all points within its calculated elastic limit. These 3D models help to keep records of the constructed artifacts and allow them to be replicated without the necessity of learning by observing the artisan constructing a given model. All existing models can be registered digitally in the local museum's documentary bases, and new models can be created with new wefts. All of these 3D digital models can be embedded with additional information such as quantitative and qualitative data from previous ethnographic research, or videos of the assembly of the artifacts. Models can be posted on free web platforms so that they can be universally replicated. In this way, these ancestral traditional techniques can be preserved, and the use of natural materials in construction, such as the interweaving of flat wooden strips, will be promoted. Aso for the impact of this study in terms of sustainability, this research clearly had a twofold objective. One aim was to preserve and promote a local tradition that has been managing local " $\mathrm{Km}$ 0 " productions of high quality wood in the forests of northern Spain (although this fact can be considered at a local level in many places in the world where the maintenance of autochthonous forests is an unequivocal source of environmental improvement). Another was to foster the substitution of polluting or non-recyclable materials such as plastic, both in the production of baskets and furniture, and in the building construction market. It should be borne in mind that construction is one of the highest resource-intensive sectors. Its high percentage of total energy consumed and high generation of greenhouse gas emissions require the substitution of non-recyclable and highly polluting materials such as plastics and concrete.

Author Contributions: Conceptualization, I.L. and A.C.; methodology, C.M. and I.L.; software, A.C. and A.S.; validation, I.L., A.C. and A.S.; formal analysis, I.L.; investigation, A.C. and C.M.; resources, A.C. and A.S.; data curation, C.M. and A.S.; writing-original draft preparation, A.C. and I.L.; writing-review and editing, I.L.; visualization, A.C. and A.S.; supervision, I.L. and A.C. All authors have read and agreed to the published version of the manuscript.

Funding: This research received no external funding.

Institutional Review Board Statement: Not applicable.

Informed Consent Statement: Not applicable. 
Data Availability Statement: The data can be found on the collaboration platform of the University of the Basque Country (https:/ / ehubox.ehu.eus/login accessed on 30 April 2021) and are available for restricted access.

Conflicts of Interest: The authors declare no conflict of interest.

\section{References}

1. European Commission. European Construction Sector Observatory. 2020. Available online: http://ec.europa.eu/growth/ sectors/construction_en (accessed on 30 April 2021).

2. Mudgal, S.; Tan, A.; Pahal, S.; Stefan, S.; Brückner, M. Sectoral Resource Maps; European Commission, DG Environment: Brussels, Belgium, 2013; p. 62.

3. Gamero, E.; Ruiz-Roso, M.; Trinidad, M.; García, R.; Cuéllar, S. Utilización de materiales naturales y reciclados para alcanzar edificios de energía casi nula. Proyecto Life Renatural NZEB. In Proceedings of the CIES2020-XVII Congresso Ibérico e XIII Congresso Ibero-Americano de Energía Solar, LNEG-Laboratório Nacional de Energia e Geologia, Lisbon, Portugal, 3-5 November 2020; pp. 1087-1090.

4. Fernando, V.; Camilla, M. 0 Km Conservation. In Vernacular Architecture. Towards a Sustainable Future; Mileto, C., Vegas, F., García, L., Cristini, V., Eds.; CRC-Balkema: London, UK, 2014; pp. 737-740.

5. Adovasio, J. Fifty years with baskets. N. Am. Archaeol. 2021, 42, 119-139. [CrossRef]

6. Pallasmaa, J. Animales Arquitectos; Gustavo Gili: Barcelona, Spain, 2020.

7. Ezquerra, A.; Gorbea, M. Caserío Igartubeiti (Ezkio-Itsaso). Arkeoikuska Inves. Arq. 1995, 1995, 460-468.

8. Ban, S. Paper Log Houses, Cebu, Philippines. 2014. Available online: https://arquitecturaviva.com/works/cabinas-de-papel-1 (accessed on 30 April 2021).

9. Miralles, E.; Tagliabue, B. Spanish Pavilion for World Expo Shangai 2010. Available online: http://www.mirallestagliabue.com/ project/spanish-pavilion-for-world-expo-shanghai-2010/ (accessed on 30 April 2021).

10. Ban, S. Hospital Daycare Center in Odate Japan. 2001. Available online: http://www.shigerubanarchitects.com/works/2001 _imai_hospital_daycare_center/index.html (accessed on 30 April 2021).

11. Ban, S. Aspen Museum, Colorado, USA. 2014. Available online: http://www.shigerubanarchitects.com/works/2014_aspen-artmuseum/index.html (accessed on 30 April 2021).

12. Ban, S. Centre Pompidou Metz, France. 2010. Available online: http://www.shigerubanarchitects.com/works/2010_centrepompidou-metz/index.html (accessed on 30 April 2021).

13. Aalto, A. Armchair 45 with Cane Seat. 1947. Available online: https://www.alvaraalto.fi/en/work/armchair-45/ (accessed on 30 April 2021).

14. Irazoki, J.L.; Lizaso, A. Zumitz, Alki. 2016. Available online: http://alki.fr/fr/produit/7219/Zumitz/ (accessed on 30 April 2021).

15. Fernández, S.; González, P.; Mozo, A. Informe Sobre la Estabilidad de las Bóvedas y el Sistema de Contrarresto de la Nave y el Crucero de la Iglesia de La Peregrina (Convento de San Francisco) en Sahagún; Ayuntamiento de Sahagún: Trycsa, Madrid, Spain, 2010.

16. Upphapong, B.; Champadaeng, S.; Sookna, S. The development of bamboo basketry according to the base of creative economy of the Thai Yo Ethnic group in Northeast Thailand. Asian Soc. Sci. 2013, 9, 231. [CrossRef]

17. Van Aken, J. Management Research Based on the Paradigm of the Design Sciences: The Quest for Field-Tested and Grounded Technological Rules. J. Manag. Stud. 2004, 41, 219-246. [CrossRef]

18. Holmström, J.; Ketokivi, M.; Hameri, A.P. Bridging practice and theory: A design science approach. Decis. Sci. 2009, 40, 65-87. [CrossRef]

19. Simon, H. The Sciences of the Artificial; Comares: Granada, Spain, 2006.

20. Gregor, S.; Hevner, A. Positioning and presenting design science research for maximum impact. MIS Quart. 2013, 337-355. [CrossRef]

21. Jones, D.; Gregor, S. The anatomy of a design theory. J. Assoc. Inform. Syst. 2007, 8, 1. [CrossRef]

22. March, S.; Smith, G. Design and natural science research on information technology. Decis. Supp. Syst. 1995, 15, 251-266. [CrossRef]

23. Hevner, A.; March, S.; Park, J.; Ram, S. Design science in information systems research. MIS Quart. 2004, 28, 75-105. [CrossRef]

24. Peffers, K.; Tuunanen, T.; Rothenberger, M.A.; Chatterjee, S. A design science research methodology for information systems research. J. Manag. Inform. Syst. 2007, 24, 45-77. [CrossRef]

25. Guillaud, S.; Vermeulen, C. Basketry in Madagascar's protected areas: Issues and consequences. Bois For. Trop. 2014, 320, 43-57. [CrossRef]

26. Wendrich, W.; Holdaway, S. Basket use, raw materials and arguments on early and Middle Holocene mobility in the Fayum, Egypt. Quatern. Internat. 2018, 468, 240-249. [CrossRef]

27. Jolie, E. The technomechanics of plains Indian coiled gambling baskets. Plains Anthrop. 2006, 51, 17-49. [CrossRef]

28. Gailiunas, P. Mad weave. J. Math. Arts 2017, 11, 40-58. [CrossRef]

29. Rosengarten, D. By the rivers of Babylon: The Lowcountry basket in slavery and freedom. In African Ethnobotany in the Americas; Springer: New York, NY, USA, 2013; pp. 123-152. 
30. Anderson, M. The fire, pruning, and coppice management of temperate ecosystems for basketry material by California Indian tribes. Hum. Ecol. 1999, 27, 79-113. [CrossRef]

31. Camp, A. Catlow Twine basketry in the western Great Basin: Use and reuse in the archaeological record. Quat. Intern. 2018, 466, 318-323. [CrossRef]

32. Lake, F.; Marks-Block, T. Effects of understory fire management treatments on California hazelnut, and ecocultural resource of the Karuk and Yurok Indians in the Pacific Northwest. In Proceedings of the 2020 ESA Annual Meeting, Online, 3-6 August 2020.

33. Caputo, A. Entretejidos ye'kuana: Oralidad, mito, artesanía. Antíp. Rev. Antrop. Arq. 2018, 31, 109-130. [CrossRef]

34. Martínez, M. Los diseños en la cestería seri. Ensayo sobre técnicas de vinculación social. An. Inst. Investig. Estéticas 2016, 38, 135-170. [CrossRef]

35. Bunn, S. Basket-work, well-being and recovery: The story from Scotland. Craft Res. 2020, 11, 39-56. [CrossRef]

36. Kvavadze, E.; Bar-Yosef, O.; Belfer-Cohen, A.; Boaretto, E.; Jakeli, N.; Matskevich, Z.; Meshveliani, T. 30,000-year-old wild flax fibers. Science 2009, 325, 1359. [CrossRef]

37. Nadel, D.; Werker, E. The oldest ever brush hut plant remains from Ohalo II, Jordan Valley, Israel (19,000 BP). Antiquity 1999, 73, 755. [CrossRef]

38. di Lernia, S.; N'siala, I.; Mercuri, A. Saharan prehistoric basketry. Archaeological and archaeobotanical analysis of the early-middle Holocene assemblage from Takarkori (Acacus Mts., SW Libya). J. Arch. Sci. 2012, 39, 1837-1853. [CrossRef]

39. Quesada, C.; Rodes, C.; Fernández, A.; Mathias, F. La cestería decorada de la Cueva de los Murciélagos (Albuñol, Granada). Complutum 1996, 6, 105-122.

40. Herrero, M.; Romero, S.; Huerta, R. Plants used in basketry production during the Early Neolithic in the north-eastern Iberian Peninsula. Veget. Hist. Arch. 2021, 1-14. [CrossRef]

41. Romero, S.; Huerta, R.; Herrero, M. The basketry at the early Neolithic site of La Draga (Banyoles, Spain). J. Arch. Sci. Rep. 2021, $35,102692$.

42. Xabier, A. La cesteria del castaño en Duralgaldea. Juan Unzueta; Arbaso: Durango, Spain, 1998.

43. Anderson, M. Indian Fire-Based Management in the Sequoia-Mixed Conifer Forests of the Central and Southern Sierra Nevada. Final Report to the Josemite Research Center, Yosemite National Park, United States Department of Interior, National Park Service, Western Region; Cooperative Agreement Order Number 8027-002; University of California Berkeley: Berkeley, CA, USA, 1993.

44. Fontales, C. Mas que Cestos. Cestería Española; Rotura: Madrid, Spain, 2013.

45. Herrera, J.; Rojo, Ú.; Parra, S.; López, C. Efecto de la temperatura de procesado sobre las propiedades mecánicas de tableros aglomerados sin resina sintética. Prospectiva 2011, 9, 75-80.

46. De Campos, C.; Rocco, F. Caracterizaccion del MDF producido a partir de Eucalipto y adhesivo Poliuretano natural. Mad. Cienc. Tec. 2004, 6, 73-84. [CrossRef]

47. Rangel, L.; Moreno, P.; Trejo, S.; Valero, S. Propiedades de tableros aglomerados de partículas fabricados con madera de Eucalyptus urophylla. Mad. Cienc. Tec. 2017, 19, 373-386. [CrossRef]

48. Plubins, N. Parametrización del Curvado de Vara de Mimbre Blanco Maduro. End of Degree Work. Bachelor's Thesis, Faculty of Architecture and Urbanism, Santiago, Chile, October 2015.

49. Rodríguez, R. Caracterización de las Propiedades Mecánicas del Bambú (Bambusa Vulgaris). Civil Eng. 2018. Available online: http:/ / hdl.handle.net/20.500.12475/352 (accessed on 30 April 2021).

50. Tomilova, M.; Smirnova, H.; Lapshin, B. The ability of materials to plaiting. Kostroma State Technol. Univ. $2013,3,17$.

51. Muscio, E.; Anaya, J. Study of the permissible bending radius of bamboo cuts. Experimental analysis with Phyllostachys bambusoides Sieb. et Zucc. Anales Edific. 2018, 4, 10-17.

52. Kovács, F. Number and twistedness of strands in weavings on regular convex polyhedra. Math. Phys. Eng. Sci. 2014, 470, 20130608. [CrossRef] [PubMed]

53. Sketchfab. Available online: https://sketchfab.com/search?q=basketry\&sort_by=-relevance\&type=models (accessed on 30 April 2021).

54. Dellosa, S.; Salvador, F. Representation of basket constructs using braid theory. In Proceedings of the 4th international conference on Computer graphics and interactive techniques in Australasia and Southeast Asia, Kuala Lumpur, Malaysia, 29 November-2 December 2006; pp. 443-451.

55. Centro de Innovación para la Formación Profesional. Manual Técnico de Formación para la Caracterización de Madera de uso Estructural. Departamento de educación Política Lingüística y Cultura Gobierno Vasco, Tknika. 2004. Available online: https:/ / normadera.tknika.eus/es/content/ficha/casta\%C3\%B1o.html (accessed on 30 April 2021).

56. Torrado, A.; Roberson, D. Failure analysis and anisotropy evaluation of 3D-printed tensile test specimens of different geometries and print raster patterns. J. Fail. Anal. Prev. 2016, 16, 154-164. [CrossRef] 